Universidade de São Paulo - USP

Faculdade de Medicina de Ribeirão Preto

Departamento Medicina Social

\title{
PREVENÇÃO QUATERNÁRIA E SUAS IMPLICAÇÕES PARA A PRÁTICA CLÍNICA: UMA REVISÃO SISTEMÁTICA
}

RIBEIRÃO PRETO - SP 


\section{MILENA SEOANE COLMENERO MUNIZ}

PREVENÇÃO QUATERNÁRIA E SUAS IMPLICAÇÕES PARA A PRÁTICA CLÍNICA: UMA REVISÃO SISTEMÁTICA

Dissertação apresentada ao Programa de Pós-Graduação da Faculdade de Medicina de Ribeirão Preto no Departamento de Medicina Social da Universidade de São Paulo para obtenção do título de Mestra em Saúde Pública.

Linha de Pesquisa: Atenção Primária à Saúde

Orientador: Prof ${ }^{a}$. Dra. Janise Braga Barros Ferreira

\section{RIBEIRÃO PRETO - SP}


Autorizo a reprodução e a divulgação total ou parcial deste trabalho, por qualquer meio convencional ou eletrônico, para fins de estudo e pesquisa, desde que citada a fonte.

Muniz, Milena Seoane Colmenero

Prevenção quaternária e suas implicações para a prática clínica: uma revisão

sistemática. / Milena Muniz; orientadora, Prof ${ }^{a}$ Dr $^{a}$ Janise Braga Barros Ferreira.

Ribeirão Preto, 2021.

59 p.: il.; $30 \mathrm{~cm}$

Dissertação de Mestrado, apresentada à Faculdade de Medicina de Ribeirão

Preto/USP ao Programa de Pós-Graduação do Departamento de Medicina Social. Área de concentração: Saúde Pública 
Nome: Milena Seoane Colmenero Muniz

Título: Prevenção quaternária e suas implicações para a prática clínica: uma revisão sistemática.

Dissertação apresentada ao Programa de Pós-Graduação do Departamento de Medicina Social da Faculdade de Medicina de Ribeirão Preto da Universidade de São Paulo para obtenção do título de Mestra em Saúde Pública.

Área de Concentração: Saúde Pública

Aprovado em: /2021

BANCA EXAMINADORA

Prof. Dr.

Instituição

Julgamento

Prof. Dr.

Instituição

Julgamento

Prof. Dr.

Instituição

Julgamento

Prof. Dr.

Instituição

Julgamento 


\section{À FAMÍLIA}

A minha família toda a gratidão pelo acolhimento e palavras de incentivo A Sylmara meus sinceros agradecimentos por toda compreensão e carinho Aos meus padrinhos pelo apoio 


\section{AGRADECIMENTOS}

A Deus e Nossa Senhora Aparecida pela proteção, resiliência e força direcionadas a mim À professora Dra. Janise Braga Barros Ferreira por me auxiliar com a construção de meu conhecimento, sempre com muita empatia e visão humanizada, uma pessoa e profissional ímpar

À professora Dra Luciane Loures Santos por ser um exemplo de médica de família e comunidade que semeia conhecimento no ambiente de formação de novos especialistas de maneira admirável

Ao Departamento de Medicina Social, da Faculdade de Medicina de Ribeirão Preto, pela oportunidade de agregar mais conhecimento a minha formação.

Agradeço à Coordenação de Aperfeiçoamento de Pessoal de Nível Superior (CAPES), pelo apoio para a realização dessa pesquisa. 


\section{RESUMO}

MUNIZ, Milena Seoane Colmenero. Prevenção quaternária e suas implicações para a prática clínica: uma revisão sistemática. 2021. 59f. Dissertação (Mestrado em Saúde Pública) - Faculdade de Medicina de Ribeirão Preto, Universidade de São Paulo, Ribeirão Preto, 2021.

O conceito de saúde proposto pela Organização Mundial de Saúde (OMS) é o completo bem estar físico, mental e social e não apenas a ausência de doença ou de enfermidade. Essa definição motiva discussões no cenário científico mundial sobre a relevância dos tratamentos e o aumento da incidência de iatrogenias. Nesse contexto insere-se a temática do exercício da prevenção quaternária, baseada na detecção dos indivíduos que estão em risco de tratamento excessivo, para propor alternativas éticas aceitáveis e sustentadas por evidências científicas. O objetivo do estudo foi identificar e sistematizar a produção de conhecimento sobre prevenção quaternária e sua implicação para a prática clínica. Como metodologia foi realizada uma revisão sistemática descritiva. A pergunta norteadora foi: Quais são as evidências produzidas sobre prevenção quaternária e sua implicação para a prática clínica? O levantamento bibliográfico foi realizado entre agosto e setembro de 2020, por meio de consulta nas bases de dados eletrônicas LILACS, PubMed, Scopus e Embase, utilizando-se o descritor prevenção quaternária. Foram selecionados os artigos publicados de 2000 a agosto de 2020, em inglês, português e espanhol. A amostra final resultou em 30 artigos com evidências que sustentam condutas focadas na prevenção quaternária em diferentes campos do conhecimento. As evidências analisadas recomendaram o fortalecimento da relação médico-paciente para à construção de cuidados menos iatrogênicos.

DESCRITORES: Prevenção Quaternária. Atenção Primária à Saúde. Revisão. 


\begin{abstract}
MUNIZ, Milena Seoane Colmenero. Quaternary prevention and its implications for clinical practice: a systematic review. 2021. 59s. Dissertation (Masters in Public Health) - Faculty of Medicine of Ribeirão Preto, University of São Paulo, Ribeirão Preto, 2021.

The concept of health proposed by the World Health Organization (WHO) is complete physical, mental and social well-being and not just the absence of disease or ailments. This definition motivates discussions on the global scientific stage about the relevance of treatments and the increased incidence of iatrogenesis. In this context, the theme of the quaternary prevention exercise, based on the detection of individuals at risk of overtreation, is inserted to propose acceptable ethical alternatives supported by scientific evidence. The objective of the study was to identify and systematize the production of knowledge on quaternary prevention and its implications for clinical practice. As a methodology, a systematic descriptive review was carried out. The guide question was: What is the evidence produced about quaternary prevention and its involvement in clinical practice? The bibliographic survey was conducted between August and September 2020, querying the ELECTRONIC databases LILACS, PubMed, Scopus and Embase using the quaternary prevention descriptor. Articles published from 2000 to August 2020 were selected in English, Portuguese and Spanish. The final sample resulted in 30 articles with evidence supporting behavior focused on Quaternary Prevention in different fields of knowledge. The evidence analyzed recommended strengthening the doctor-patient relationship for the construction of less iatrogenic care.
\end{abstract}

DESCRIPTORS: Quaternary Prevention. Primary health care. Review 


\section{RESUMEN}

MUNIZ, Milena Seoane Colmenero. Prevención cuaternaria y sus implicaciones para la práctica clínica: una revisión sistemática. 2021. 59h. Disertación (Maestría en Salud Pública) - Facultad de Medicina de Ribeirão Preto, Universidad de São Paulo, Ribeirão Preto, 2021

El concepto de salud propuesto por la Organización Mundial de la Salud (OMS) es el completo bienestar físico, mental y social y no solo la ausencia de enfermedades o dolencias. Esta definición motiva discusiones en el escenario científico mundial sobre la relevancia de los tratamientos y la mayor incidencia de iatrogénesis. En este contexto, se inserta el tema del ejercicio de prevención cuaternaria, basado en la detección de individuos que están en riesgo de sobretratamiento para proponer alternativas éticas aceptables respaldadas por evidencia científica. El objetivo del estudio fue identificar y sistematizar la producción de conocimiento sobre prevención cuaternaria y sus implicaciones para la práctica clínica. Como metodología, se realizó una revisión sistemática descriptiva. La pregunta guía fue: ¿Cuál es la evidencia producida sobre la prevención cuaternaria y su implicación para la práctica clínica? La encuesta bibliográfica se realizó entre agosto y septiembre de 2020, consultando las bases de datos electrónicas LILACS, PubMed, Scopus y Embase utilizando el descriptor de prevención cuaternaria. Se seleccionaron artículos publicados de 2000 a agosto de 2020 en inglés, portugués y español. La muestra final resultó en 30 artículos con evidencia que apoya la conducta enfocada en la Prevención Cuaternaria en diferentes campos del conocimiento. La evidencia analizada recomendó el fortalecimiento de la relación médico-paciente para la construcción de una atención menos iatrogénica.

Descriptores: Prevención Cuaternaria. Atención primaria de salud. Revisión 


\section{LISTA DE FIGURAS}

Figura 1. Fluxograma do processo de seleção dos artigos baseado no modelo Prisma ${ }^{12}$ 


\section{LISTA DE TABELAS}

Tabela 1 Artigos selecionados segundo título, autor, tipo de estudo, ano de publicação, e país de estudo e de publicação. 24

Tabela 2 Principais achados dos estudos em relação à área de aplicação da PQ e as suas

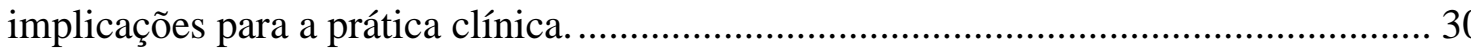


LISTA DE ABREVIATURAS

$\begin{array}{ll}\text { APS } & \text { Atenção Primária à Saúde } \\ \text { DeCS } & \text { Descritores em Ciências da Saúde } \\ \text { EMBASE } & \text { Excerpta Medica dataBASE } \\ \text { ESF } & \text { Estratégia de Saúde da Família } \\ \text { LILACS } & \text { Latin American and Caribbean Health Sciences Literature } \\ \text { MFC } & \text { Médico de Família e Comunidade } \\ \text { MS } & \text { Ministério da Saúde } \\ \text { PIASS } & \text { Programa de Interiorização de Ações de Saúde do Nordeste } \\ \text { PICO } & \text { Population (população), Intervention (intervenção), Comparison } \\ \text { (Comparação) da intervenção (se aplicável) e Outcome (Resultados) } \\ \text { PICS } & \text { Práticas Integrativas e Complementares em Saúde } \\ \text { PNAB } & \text { Política Nacional de Atenção Básica } \\ \text { PQ } & \text { Prevenção Quaternária } \\ \text { PSA } & \text { Antígeno prostático específico } \\ \text { PubMed } & \text { Public/Publisher Medline da US National Library of Medicine } \\ \text { SCOPUS } & \text { Sci Verse SCOPUS } \\ \text { TDAH } & \text { Transtorno de Déficit de Atenção e Hiperatividade } \\ \text { USPSTF } & \text { World Conference of Family Doctors } \\ \text { WONCA } & \end{array}$




\section{SUMÁRIO}

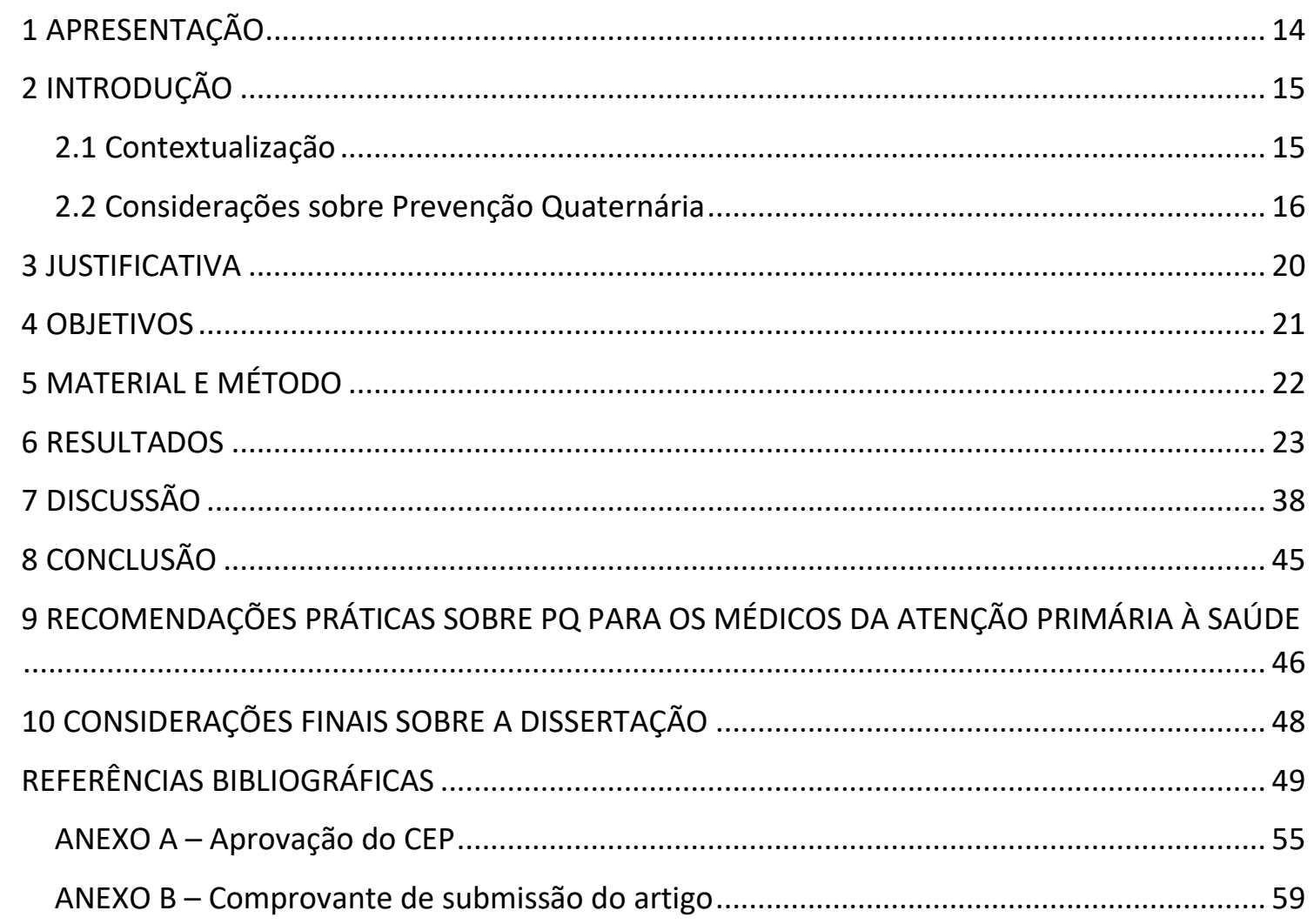




\section{APRESENTAÇÃO}

Em 2004, ingressei na Universidade de Ribeirão Preto, no curso de bacharelado em Medicina, concluindo a graduação em 2010. Realizei diversos estágios curriculares dentro da disciplina de Medicina de Família e Comunidade, onde tive contato com o processo de trabalho desenvolvido na Atenção Primária em Saúde e mais especificamente na Estratégia de Saúde da Família.

Após o término da graduação, trabalhei por dois anos em alguns cenários de Pronto Atendimento. Durante esse período pude acompanhar quais as patologias que geravam maiores necessidades de cuidados em serviços de urgências e emergências., levando a reflexões sobre quais formas poderíamos atuar para diminuição da incidência e da morbimortalidade.

Em 2014, fui aprovada no Programa de Residência Médica em Medicina de Família e Comunidade do HCFMRP, por 02 anos atuando em cenários de Atenção Primária em Saúde, e adquirindo ferramentas para construir relações com pacientes, mais sólidas, motivar o cuidado longitudinal

No ano de 2017, iniciei as atividades como médica na Unidade de Saúde da Família do Jardim Paiva, onde tive a oportunidade de participar da transformação de Unidade Básica para Unidade de Saúde da Família. Atuando nesse local por 02 anos, e posteriormente nos 9 Núcleos de Saúde da Família ligados à Faculdade de Medicina de Ribeirão Preto, até março de 2020.

Em 2020, inicio minhas atividades como médica de família e comunidade na Unidade de Saúde da Família do Jardim Marchesi, associando prática clínica, coordenação e docência.

A trajetória dentro da Atenção Primária em Saúde e suas relações interpessoais enriquecedoras, com equipes e pacientes, estimularam o interesse pelo cuidado realizado de forma menos iatrogênica, centrado no paciente, dentro de alternativas éticas aceitáveis. Dessa forma, o ingresso no Programa de Pós-Graduação da Faculdade de Medicina de Ribeirão Preto no Departamento de Medicina Social, foi uma consequência de todo esse processo. 


\section{INTRODUÇÃO}

\subsection{Contextualização}

A Atenção Primária em Saúde (APS) é definida pela Declaração de Alma-Ata como cuidados de saúde essenciais baseados em métodos práticos, cientificamente sólidos, socialmente aceitos e tecnologia universalmente acessível aos indivíduos e às famílias. Sendo o primeiro nível de contato dos indivíduos, das famílias e da comunidade com o sistema nacional de saúde caracteriza-se como elemento essencial de um processo contínuo de saúde ${ }^{1}$. Um dos primeiros países a estruturar esse modelo de atenção primária vista como uma rede regionalizada e hierarquizada de saúde, com estratificação de complexidade, foi o Reino Unido, em 1920, através do Relatório Dawson que orientou a formação do sistema de saúde britânico, o qual, influenciou, posteriormente, os modelos assistenciais de outros países ${ }^{2}$.

No Brasil, a organização das ações e serviços da APS ocorreu de forma gradativa, inicialmente, com a criação dos Centros de Saúde Escola e, posteriormente, o Serviço Especial de Saúde Pública e o Programa de Interiorização de Ações de Saúde do Nordeste $(\text { PIASS })^{3}$. Em seguida, com o movimento sanitário, as concepções da APS foram incorporadas à ideia reformista do setor saúde, culminando, em 1988, com o Sistema Único de Saúde (SUS), inscrito na nova Constituição brasileira. O propósito foi de reorganização do modelo assistencial, priorizando a universalidade do acesso à saúde, fundamentado em princípios doutrinários e organizativos ${ }^{3}$.

Atualmente, a Política Nacional de Atenção Básica (PNAB) delimita um novo momento da APS para o país, apresentando proposições que carecem de melhor compreensão quanto ao seu desenvolvimento e resultados. Por um lado, a PNAB prevê a revisão na composição das equipes de saúde e, por outro, a ampliação de suas atribuições, tais como, em casos excepcionais, a realização de procedimentos pelos agentes comunitários de saúde como curativos, aferição de pressão arterial e glicemia. Além disso, estabelece a padronização de uma carteira de serviços e a possibilidade de atendimento do usuário em qualquer unidade de sua preferência. Em relação ao financiamento, essa normativa altera o repasse do Piso de Atenção Básica (PAB fixo - 
valor per capita por município) com a possibilidade destinação de maiores valores àqueles municípios com maior densidade demográfica e mais pobres 4 .

Nesse contexto, insere-se a Estratégia de Saúde da Família (ESF) indicada pelo Ministério da Saúde (MS) como paradigma de expansão, qualificação e consolidação da APS no país. Essa orientação se deve, principalmente, às peculiaridades do processo de trabalho da ESF que podem aumentar a resolutividade do cuidado, com impacto positivo na saúde dos indivíduos, famílias e comunidades, com satisfatória relação de custoefetividade $^{5}$. Dados do MS indicam que, atualmente, a ESF atende a $133.710 .730 \mathrm{de}$ pessoas, ou seja, 63,62\% da população brasileira, por meio de 42.105 equipes de saúde da família ${ }^{6 .}$

Importante notar que a ESF ao propor uma nova forma de organização do processo de trabalho na APS, redireciona o olhar sobre a pessoa e o cuidado a ela prestado. A ESF parte do entendimento de que os usuários do sistema de saúde são seres biopsicossociais, ou seja, encontram-se inseridos em um território-vivo e, por isso, sofrem diversas influências sociais, econômicas, ambientais e biológicas. Ainda, podem ser impactados negativamente com o resultado da própria ação dos serviços de saúde, em decorrência da adoção de certas práticas que podem levar ao adoecimento ${ }^{6}$.

\subsection{Considerações sobre Prevenção Quaternária}

Nesta lógica, surge em 1999 o conceito de Prevenção Quaternária (PQ), proposto pelo belga Marc Jamoulle e oficializado em 2003 pela World Conference of Family Doctors (WONCA). A PQ foi, então, definida como "a detecção de indivíduos em risco de tratamento excessivo, para protegê-los de novas intervenções médicas inapropriadas e sugerir-lhes alternativas eticamente aceitáveis"7.

A discussão sobre o tema PQ tornou-se presente, nos últimos anos com maior frequência, pois o aumento da incidência de iatrogenias atingiu o patamar de terceira causa de morte nos Estados Unidos da América, isto é, tornou-se um problema de saúde pública.

$\mathrm{O}$ excesso de exames solicitados e a medicalização de fatores de risco podem causar danos biológicos e sociais aos indivíduos expostos, gerando ansiedade, na medida 
em que caracterizam o paciente como alguém "doente" e afetam o desempenho do seu papel em sua comunidade. Além disso, podem alterar os modos de adoecimento e de enfrentamento das doenças ${ }^{8}$.

De modo geral, os fatores de risco para o desenvolvimento de doenças em indivíduos dizem respeito a aspectos do comportamento pessoal, exposição ambiental e aspectos biológicos. Esses fatores são comprovadamente correlacionados a determinadas condições de saúde, por isso, considera-se importante o enfoque na prevenção para a manutenção da saúde das pessoas. No entanto, grosso modo, tornou-se habitual o entendimento de fatores de risco como agentes etiológicos da doença ${ }^{9}$. Segundo Gérvas \& Pérez-Fernández pela própria prática médica pode-se transformar os indivíduos sãos em indivíduos sãos preocupados, depois em sãos estigmatizados e em pseudoenfermos. De outra forma, os pacientes podem ser expostos a danos desnecessários, previsíveis e imprevisíveis dentro dos serviços de saúde ${ }^{10}$.

Ademais, os profissionais da área da saúde, pressionados pela demanda assistencial e burocrática, apresentam tempo restrito para que seja feita educação em saúde, observação atenta e espera permitida. Além disso, aspectos relacionados à judicialização da saúde fazem com que as prescrições e solicitações de exames complementares sejam cada vez mais frequentes. Todos esses fatores dificultam a atividade profissional e podem interferir diretamente na execução das práticas de saúde.

A compreensão da PQ pode ser facilitada, por exemplo, por meio da discussão acerca dos rastreamentos que são um conjunto de exames e testes que podem ser realizados em uma população aparentemente sadia, para diagnóstico de doenças latentes ou em estágio precoce. $\mathrm{O}$ intuito é diminuir a morbidade e mortalidade relacionadas à determinadas doenças ${ }^{11}$.

Entretanto, é preciso que os profissionais da saúde analisem criticamente a necessidade de rastreio, baseado no perfil epidemiológico da população onde irão aplicar testes e colocar em prática as recomendações das evidências científicas.

Assim, quando o rastreamento não traz benefícios reais levando o paciente a uma exposição desnecessária, com todos os riscos inerentes às intervenções médicas, sem que haja uma influência estatística significante expressada pela melhoria dos indicadores, está recomendado o uso da PQ. 
Pode-se observar que, na atualidade, entidades reconhecidas internacionalmente como a United States Preventive Services Task Force (USPSTF) e o Canadian Task Force on Preventive Health Care vêm desenvolvendo estudos para fundamentar a prática da PQ. Essas instituições, por exemplo, não recomendam que sejam realizadas ações programáticas para rastreamento de neoplasia prostática. Tal recomendação está apoiada em estudos que fizeram o acompanhamento longitudinal de homens, os quais realizavam anualmente o toque retal associado ou não à dosagem de antígeno prostático específico (PSA). Os resultados desses estudos mostraram que essa prática não trazia benefício real para a saúde masculina ${ }^{12}$.

Atualmente, há uma indicação de revisão do conceito de PQ que propõe ampliar a sua aplicação para proteção de um maior contingente de indivíduos em relação a intervenções médicas que possam causar mais danos do que benefícios. Pode-se afirmar que as pessoas estão expostas a medidas iatrogênicas em todos os ciclos de vida e a utilização de uma definição mais abrangente de PQ poderá beneficiar todos os pacientes e não só aqueles caracterizados como os maiores expostos a risco de sobrediagnósticos e sobretratamentos ${ }^{13}$.

O momento atual também é de discussão da Prevenção Quaternária e o uso de Práticas Integrativas e Complementares em Saúde (PICS)que desde 2006 são oferecidas no Sistema Único de Saúde. No geral, as PICS estimulam o autocuidado e diminuem a sobremedicalização ${ }^{14}$.

Outro ponto importante a ser lembrado é a discussão envolvendo a prescrição de hidroxicloroquina e cloroquina, sob a luz da Prevenção Quaternária, de forma terapêutica e/ou profilática para população susceptível ou acometida pela doença classificada como Coronavirus Disease 2019 (COVID-19). Estudos recentes demonstram que 80\% dos quadros são leves e autolimitados, tendo em vista tal situação, seriam medicalizados $80 \%$ dos indivíduos que melhorariam espontaneamente ${ }^{15}$.

Em síntese, é preciso ter clareza que a ação de saúde proposta não vá causar mais malefícios do que benefícios aos pacientes. Nessa ótica, a discussão em larga escala da $\mathrm{PQ}$, ainda pouco realizada no Brasil, pode e deve acontecer de modo estratégico, por meio da educação permanente no SUS e durante a graduação e pós-graduação dos cursos da área da saúde, para que práticas de excelência possam ser desenvolvidas e consolidadas, com o intuito de reduzir a medicalização e a iatrogenia do cuidado. 
Contudo, é preciso que haja uma boa relação médico-paciente que permita um diálogo franco sobre as possíveis ações/procedimentos disponíveis, no setor saúde, e seus reais benefícios e as justificativas para que eles sejam ou não indicados.

Assim, tem-se a convicção que na ESF, moldada por seus atributos essenciais (primeiro contato, integralidade, longitudinalidade e coordenação) e derivados (orientação familiar, comunitária e competência cultural) exista maior chance de se obter êxito no processo do cuidado e de se aplicar a PQ.

Um dos pilares da prática do médico de família e comunidade (MFC) é a abordagem centrada na pessoa, que viabiliza a melhor compreensão do binômio saúdedoença, por meio da interação com o indivíduo, a família e a comunidade. Além disso, essa abordagem considera, na elaboração do projeto terapêutico, o significado do adoecimento para a pessoa, ratificando a importância da autonomia do sujeito na condução de sua condição de saúde.

Nesse cenário, partindo-se da premissa de que prática da PQ é importante para não expor os pacientes à intervenção médica desnecessária configura-se o problema de pesquisa: qual o conhecimento que os MFC e/ou médicos que atuam na APS têm acerca da PQ? 


\section{JUSTIFICATIVA}

Sabe-se que a PQ gera um cuidado menos iatrogênico, individualizado que favorece o uso racional de recursos. Além disso que o médico de família é o especialista com maiores chances de sucesso em sua realização, pois tem a relação médico-paciente favorecida pela oferta do cuidado longitudinal. 


\section{OBJETIVOS}

3.1 Identificar e sistematizar a produção de conhecimento sobre prevenção quaternária e sua implicação para a prática clínica.

3.2 Elaborar uma lista de recomendações sobre o exercício da prevenção quaternária na atenção primária à saúde. 


\section{MATERIAL E MÉTODO}

Trata-se de uma revisão sistemática descritiva ${ }^{16-18}$ utilizando-se a estratégia PICO, sendo "P" a população (população em geral), "I" o fenômeno de interesse (prevenção quaternária), "C" comparação (sem comparação) e "O" resultado (implicação para a prática clínica) para elaborar a pergunta norteadora: "Quais são as evidências científicas produzidas sobre PQ e suas implicações para a prática clínica?”

O levantamento bibliográfico foi realizado com consulta às bases de dados eletrônicas LILACS, PubMed, Scopus e Embase, por meio do descritor/termo "prevenção quaternária". Como critério de inclusão selecionou-se artigos publicados de janeiro de 2000 a agosto de 2020, em inglês, português e espanhol, cujo acesso ao texto integral foi permitido. Adotou-se como critérios de exclusão: teses, dissertações e notas editoriais. Aqueles artigos que discutiam apenas o conceito de PQ também foram excluídos.

Com o auxílio do software Rayyan ${ }^{19}$ elaborou-se o banco de artigos e após a eliminação das duplicações realizou-se a avaliação por três revisores, de forma independente. Primeiramente, procedeu-se a leitura do título e do resumo, executando as exclusões de acordo com os critérios adotados. Os três revisores discutiram e resolveram, consensualmente, as discordâncias em relação à avaliação cega. Posteriormente, os revisores procederam a leitura na íntegra dos artigos selecionados, sendo composta a amostra final da revisão. A análise descritiva dos estudos selecionados compreendeu, no primeiro momento, a extração dos dados: título do artigo, autores, tipo do estudo, ano e país. No segundo momento realizou-se a sistematização e a interpretação das evidências sobre PQ e sua implicação para a prática clínica.

Posteriormente, tendo como base os resultados da revisão sistemática foi elaborada uma lista de recomendações por ciclo de vida, destacando-se pontos a serem observados na prática da PQ, principalmente, no cenário da APS.

Vale pontuar que este estudo integra um projeto de pesquisa intitulado “Conhecimentos dos médicos da atenção primária à saúde acerca da prevenção quaternária: estudo transversal, que foi aprovado pelo CEP do Centro de saúde Escola da Faculdade de Medicina de Ribeirão Preto da Universidade de São Paulo (CAAE: 01841218.6.0000.5414). 


\section{RESULTADOS}

A estratégia de busca identificou 238 artigos, dentre os quais 56 apresentavam-se em mais de uma base de dados, sendo 78 da LILACS, 82 da Scopus, 21 da Embase e 57 da PubMed. Após leitura dos títulos e dos resumos, selecionamos 94 manuscritos para a leitura integral, restando na amostra final 30 artigos (Figura 1).

Figura 1. Fluxograma do processo de seleção dos artigos baseado no modelo Prisma ${ }^{12}$

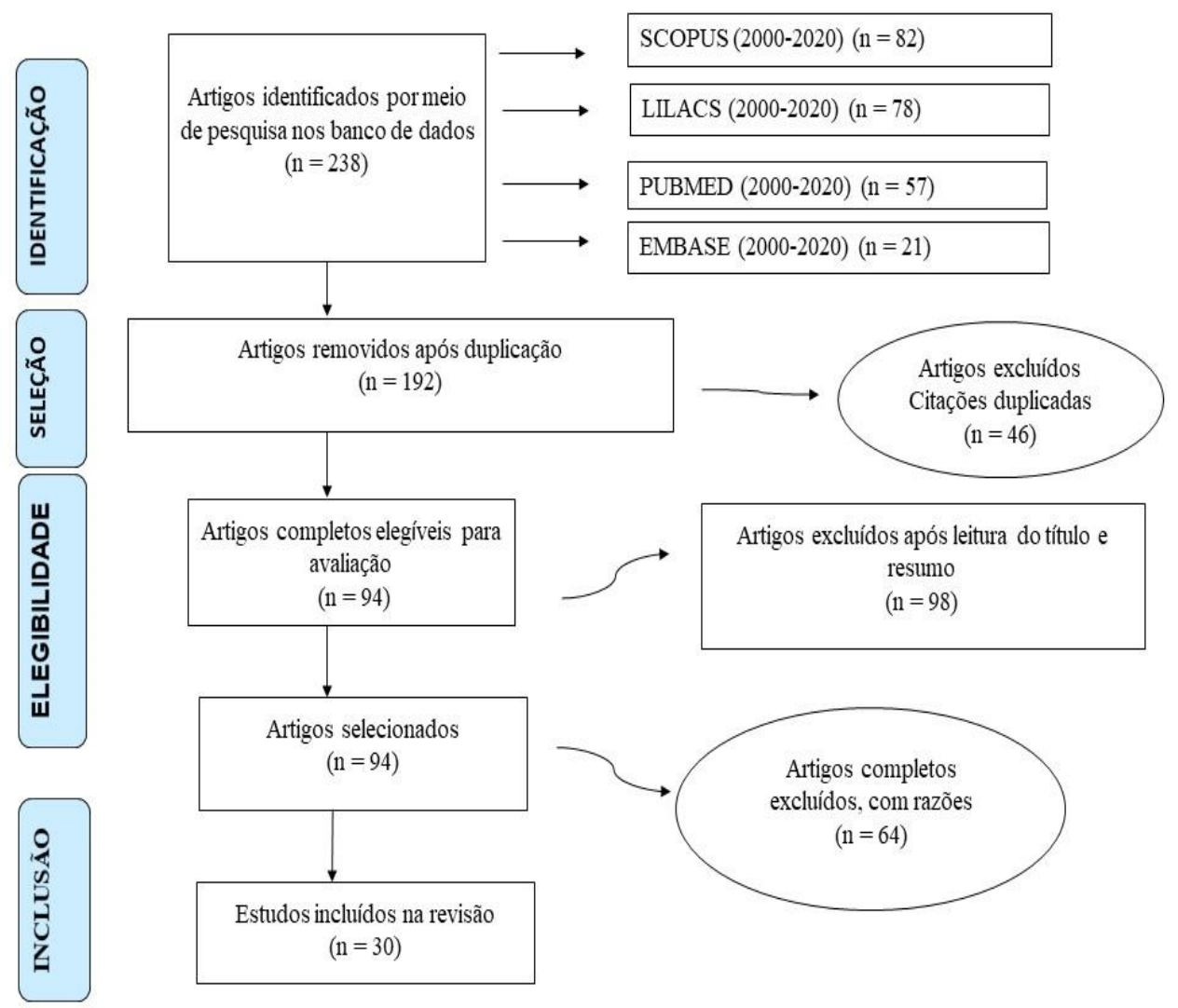

Os 30 artigos selecionados apresentaram a seguinte distribuição de acordo com idioma de publicação: dezessete $(56,7 \%)$ em inglês, nove $(30,0 \%)$ em espanhol e quatro $(13,3 \%)$ em português. Quanto ao país de origem do estudo, dois ${ }^{20,21}$ originaram-se dos Estados Unidos, dois ${ }^{22,23}$ da Índia, dois ${ }^{26,42}$ do Uruguai, três ${ }^{24-26}$ de Portugal, quatro ${ }^{8,27-29}$ do Brasil, nove ${ }^{9,26,30-36}$ da Espanha e outros oito ${ }^{37-44}$ oriundos de oito diferentes países. Os primeiros seis artigos ${ }^{9,30-34}$ da revisão foram de origem espanhola. Em relação ao nível 
de evidências dos artigos selecionados verificou-se: 26 estudos descritivos (nível 3), dois relatos de casos (nível 3) e dois analíticos (nível 2) ${ }^{45}$. A tabela 1 sintetiza os dados extraídos dos artigos selecionados: título, autor, tipo de estudo, ano, país de origem e de publicação.

Tabela 1 Artigos selecionados segundo título, autor, tipo de estudo, ano de publicação, e país de estudo e de publicação.

\begin{tabular}{|c|c|c|c|c|c|}
\hline Título & Autores & $\begin{array}{l}\text { Tipo de } \\
\text { Estudo }\end{array}$ & Ano & $\begin{array}{l}\text { País de } \\
\text { origem } \\
\text { Estudo }\end{array}$ & $\begin{array}{c}\text { País de } \\
\text { publicação }\end{array}$ \\
\hline $\begin{array}{l}\text { Genética y } \\
\text { prevención } \\
\text { cuaternaria.El } \\
\text { ejemplo de la } \\
\text { hemocromatosis }\end{array}$ & $\begin{array}{l}{ }^{10} \text { Gérvas J, } \\
\text { Fernández MP. }\end{array}$ & Descritivo & 2003 & Espanha & Espanha \\
\hline $\begin{array}{l}\text { Moderación en la } \\
\text { actividad médica } \\
\text { preventiva y } \\
\text { curativa. Cuatro } \\
\text { ejemplos de } \\
\text { necesidad de } \\
\text { prevención } \\
\text { cuaternaria en } \\
\text { España }\end{array}$ & ${ }^{31}$ Gérvas J. & Descritivo & 2006 & Espanha & Espanha \\
\hline $\begin{array}{l}\text { Uso y abuso del } \\
\text { poder médico } \\
\text { para definir } \\
\text { enfermedad } \\
\text { y factor de riesgo, } \\
\text { en relación con la } \\
\text { prevención } \\
\text { cuaternaria }\end{array}$ & $\begin{array}{l}{ }^{46} \text { Gérvas J, } \\
\text { Fernández MP. }\end{array}$ & Descritivo & 2006 & Espanha & Espanha \\
\hline
\end{tabular}




\begin{tabular}{|c|c|c|c|c|c|}
\hline $\begin{array}{l}\text { Iatrogenia y } \\
\text { prevención } \\
\text { cuaternaria en } \\
\text { salud mental }\end{array}$ & $\begin{array}{l}{ }^{32} \text { Alberto Ortiz } \\
\text { Lobo; Vicente } \\
\text { Ibáñez Rojo; }\end{array}$ & Descritivo & 2011 & Espanha & Espanha \\
\hline $\begin{array}{l}\text { El enigma de la } \\
\text { prevención } \\
\text { cuaternaria en } \\
\text { atención } \\
\text { primaria.Cuándo } \\
\text { hacer y cuándo } \\
\text { no hacer (a } \\
\text { propósito de } 2 \\
\text { casos) }\end{array}$ & $\begin{array}{l}{ }^{33} \text { Cucalón JM, } \\
\text { Guiu M. }\end{array}$ & $\begin{array}{l}\text { Relato de } \\
\text { caso }\end{array}$ & 2012 & Espanha & Espanha \\
\hline $\begin{array}{l}\text { Prevención } \\
\text { cuaternaria em } \\
\text { ancianos }\end{array}$ & ${ }^{34}$ Gérvas J. & Descritivo & 2012 & Espanha & Espanha \\
\hline
\end{tabular}

American Society ${ }^{20}$ Smith TJ et al. $\quad$ Descritivo 2012 EUA $\quad$ EUA

of Clinical

Oncology

Provisional

Clinical Opinion:

The Integration

of Palliative Care

Into Standard

Oncology Care

The four steps in ${ }^{37}$ Liverani CA. Descritivo $2013 \quad$ Itália $\quad$ Suíça

the prevention of

human

papillomavirus-

associated

neoplasia:

considerations for

preventive 
measures,

screening, disease

impact, and

potential

overtreatments in

HPV-related

pathology

Rastreamento do ${ }^{24}$ Santos JA. $\quad$ Descritivo 2013 Portugal $\quad$ Brasil

câncer de mama:

as três luzes do

semáforo

\begin{tabular}{|c|c|c|c|c|c|}
\hline $\begin{array}{l}\text { Quaternary } \\
\text { prevention and } \\
\text { diabetes }\end{array}$ & $\begin{array}{l}{ }^{22} \text { Kalra S, } \\
\text { Sreedevi A, } \\
\text { Unnikrishnan, } \\
\text { AG }\end{array}$ & Descritivo & 2014 & Índia & Paquistão \\
\hline $\begin{array}{l}\text { Quaternary } \\
\text { prevention as a } \\
\text { basis for rational } \\
\text { approach to the } \\
\text { patient in family } \\
\text { practice. }\end{array}$ & $\begin{array}{l}{ }^{38} \text { Baricević IZ, } \\
\text { Botica MV, } \\
\text { Pavlic-Renar, I }\end{array}$ & Descritivo & 2014 & Croácia & Croácia \\
\hline $\begin{array}{l}\text { Cuidado (!) na } \\
\text { prevenção do } \\
\text { câncer: ética, } \\
\text { danos e } \\
\text { equívocos }\end{array}$ & ${ }^{29}$ Tesser CD. & Descritivo & 2014 & Brasil & Brasil \\
\hline $\begin{array}{l}\text { Multimorbidity } \\
\text { and quaternary } \\
\text { prevention }\end{array}$ & $\begin{array}{l}{ }^{39} \text { Mangin, Dee; } \\
\text { Heath, Iona; }\end{array}$ & Descritivo & 2015 & Inglaterra & Brasil \\
\hline $\begin{array}{l}\text { ¿ Overscreening } \\
\text { o prevención a } \\
\text { escala humana? } \\
\text { Tamizaje }\end{array}$ & ${ }^{47}$ Báez MP. & Descritivo & 2015 & Uruguai & Brasil \\
\hline
\end{tabular}




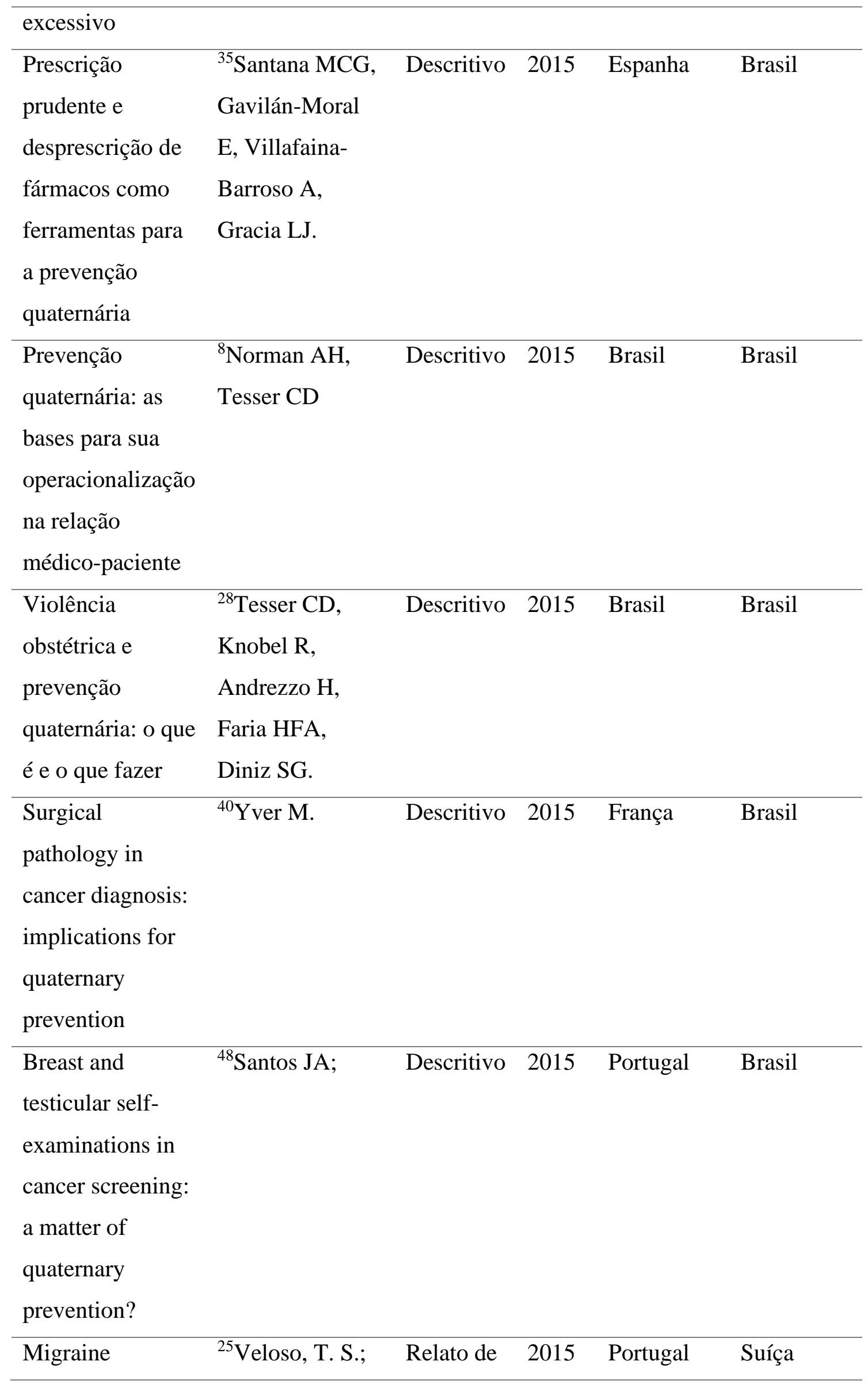




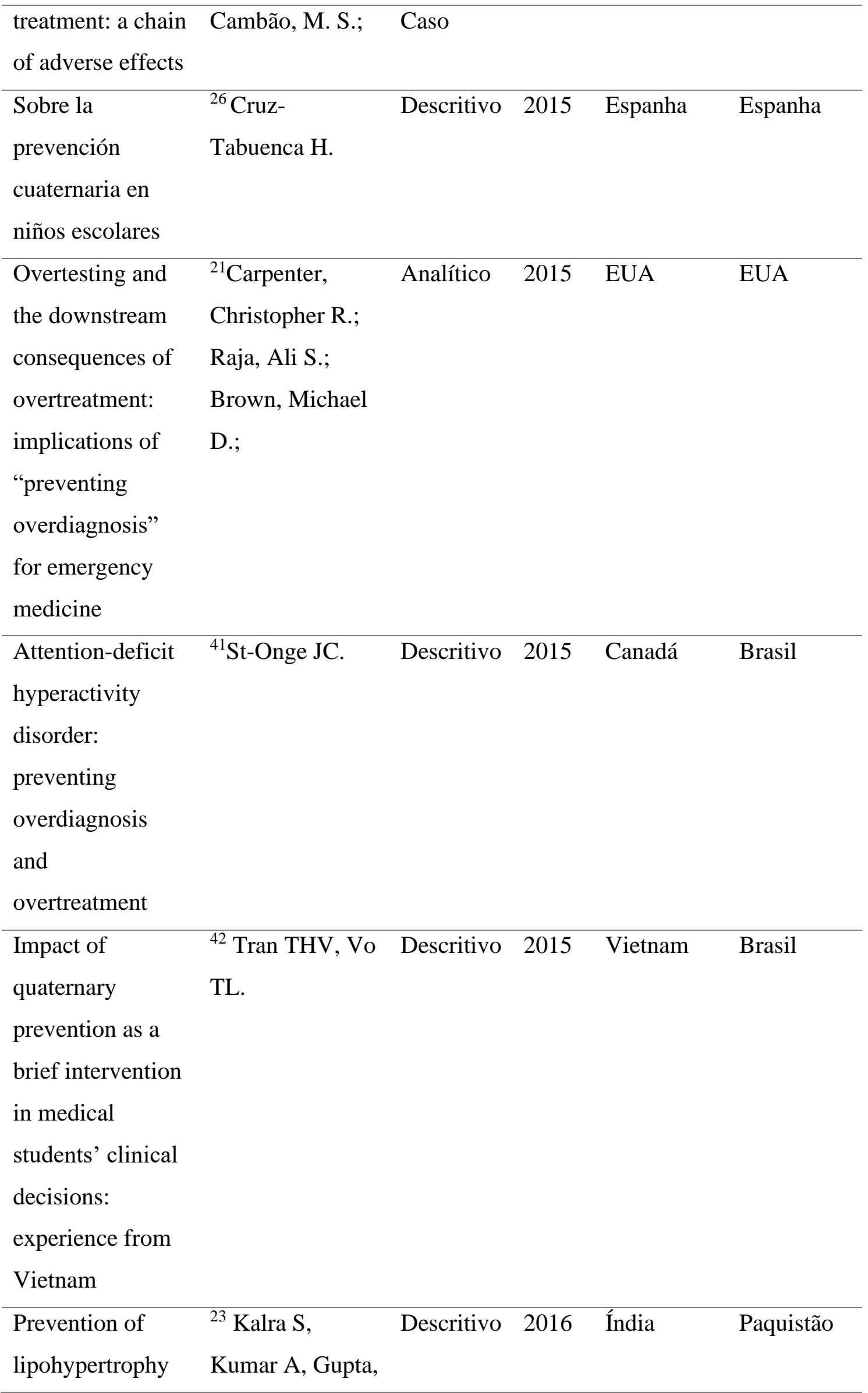




\begin{tabular}{|c|c|c|c|c|c|}
\hline & Y. & & & & \\
\hline $\begin{array}{l}\text { Primary care } \\
\text { physicians' } \\
\text { action plans for } \\
\text { responding to } \\
\text { results of } \\
\text { screening tests } \\
\text { based on the } \\
\text { concept of } \\
\text { quaternary } \\
\text { prevention }\end{array}$ & $\begin{array}{l}{ }^{43} \text { Bae J-M, } \\
\text { Jamoulle M. }\end{array}$ & Analítico & 2016 & Coreia & Coreia \\
\hline $\begin{array}{l}\text { Medical overuse } \\
\text { and quaternary } \\
\text { prevention } \\
\text { primary care-A } \\
\text { qualitative study } \\
\text { with general } \\
\text { practitioners }\end{array}$ & $\begin{array}{l}{ }^{44} \text { Alber K, } \\
\text { Kuehlein T, } \\
\text { Schedlbauer A, } \\
\text { Schaffer S. }\end{array}$ & Descritivo & 2017 & Alemanha & $\begin{array}{l}\text { Reino } \\
\text { Unido }\end{array}$ \\
\hline $\begin{array}{l}\text { Impact of } \\
\text { overdiagnosis } \\
\text { and } \\
\text { overtreatment on } \\
\text { the patient, the } \\
\text { health system and } \\
\text { society }\end{array}$ & $\begin{array}{l}{ }^{36} \text { Coll-Benejam } \\
\text { T, Bravo-Toledo } \\
\text { R, Marcos-Calvo } \\
\text { MP, Astier-Peña } \\
\text { MP }\end{array}$ & Descritivo & 2018 & Espanha & Espanha \\
\hline $\begin{array}{l}\text { A not-so-blue } \\
\text { November: } \\
\text { debating } \\
\text { screening of } \\
\text { prostate cancer } \\
\text { and men's health }\end{array}$ & $\begin{array}{l}{ }^{27} \text { Modesto } \\
\text { AADA, } \\
\text { Lima RLB, } \\
\text { D'Angelis AC, } \\
\text { Augusto DK. }\end{array}$ & Descritivo & 2018 & Brasil & Brasil \\
\hline $\begin{array}{l}\text { Vacunación } \\
\text { contra el virus del }\end{array}$ & $\begin{array}{l}{ }^{49} \text { Báez MP, } \\
\text { Jamoulle M }\end{array}$ & Descritivo & 2019 & Uruguai & Brasil \\
\hline
\end{tabular}


papiloma humano

a la luz de la

prevención

cuaternaria

Fonte: Produzido pelos autores, 2020.

A tabela 2 traz os principais achados dos estudos em relação à PQ quanto à área de aplicação na prática clínica.

Tabela 2 Principais achados dos estudos em relação à área de aplicação da PQ e as suas implicações para a prática clínica.

\begin{tabular}{|c|c|c|}
\hline & le Aplicação & ática \\
\hline $\begin{array}{l}{ }^{43} \text { Primary care } \\
\text { physicians' action } \\
\text { plans for } \\
\text { responding to } \\
\text { results of } \\
\text { screening tests } \\
\text { based on the } \\
\text { concept } \\
\text { quaternary }\end{array}$ & $\begin{array}{l}\text { A aplicação do conceito de } \\
\text { PQ auxiliando os médicos } \\
\text { de família e comunidade a } \\
\text { obter melhores insights } \\
\text { sobre testes de triagem } \\
\text { destinados à prevenção de } \\
\text { doenças crônicas não } \\
\text { transmissíveis. }\end{array}$ & $\begin{array}{l}\text { Os autores sugerem que os testes de } \\
\text { triagem para as doenças crônicas não } \\
\text { transmissíveis sejam personalizados } \\
\text { para atender às características } \\
\text { individuais, ao invés de serem } \\
\text { realizados com base em diretrizes } \\
\text { gerais. }\end{array}$ \\
\hline $\begin{array}{l}{ }^{8} \text { Prevenção } \\
\text { quaternária: as } \\
\text { bases para sua } \\
\text { operacionalização } \\
\text { na relação } \\
\text { médico-paciente. }\end{array}$ & $\begin{array}{l}\text { A PQ implicando no } \\
\text { fortalecimento e na revisão } \\
\text { crítica do raciocínio clínico } \\
\text { de médicos de família. }\end{array}$ & $\begin{array}{l}\text { O manuscrito oferece uma estrutura } \\
\text { conceitual para discutir } \\
\text { operacionalmente a PQ originada da } \\
\text { relação médico-paciente, que é } \\
\text { relevante para as práticas de serviços } \\
\text { e ambientes de ensino, como } \\
\text { programas de residência em } \\
\text { medicina de família e comunidade. }\end{array}$ \\
\hline $\begin{array}{l}{ }^{21} \text { Overtesting and } \\
\text { the downstream } \\
\text { consequences of } \\
\text { overtreatment: } \\
\text { implications of }\end{array}$ & $\begin{array}{l}\text { O conceito de PQ } \\
\text { discutido em relação a sua } \\
\text { implementação, na atenção } \\
\text { às urgências/emergências. }\end{array}$ & $\begin{array}{l}\text { Os autores descrevem e avaliam as } \\
\text { barreiras e as oportunidades para se } \\
\text { reduzir o excesso de testes e } \\
\text { intervenções nas unidades de } \\
\text { atendimento de urgência e }\end{array}$ \\
\hline
\end{tabular}




\begin{tabular}{|c|c|c|}
\hline $\begin{array}{l}\text { "preventing } \\
\text { overdiagnosis" } \\
\text { for emergency } \\
\text { medicine }\end{array}$ & & emergência. \\
\hline $\begin{array}{l}{ }^{26} \text { Sobre la } \\
\text { prevención } \\
\text { cuaternaria en } \\
\text { niños escolares }\end{array}$ & $\begin{array}{l}\text { Discussão sobre a PQ em } \\
\text { uma condição ortopédica } \\
\text { específica, com } \\
\text { prevalência significativa } \\
\text { na população de escolares. }\end{array}$ & $\begin{array}{l}\text { O artigo discute o diagnóstico de } \\
\text { escoliose que muitas vezes é } \\
\text { realizado em escolares e sua real } \\
\text { necessidade de investigação com } \\
\text { exames complementares e questões } \\
\text { sobre o tratamento, sendo o paciente } \\
\text { assintomático. }\end{array}$ \\
\hline $\begin{array}{l}{ }^{31} \text { Moderación en } \\
\text { la actividad } \\
\text { médica } \\
\text { preventiva } \\
\text { curativa. Cuatro } \\
\text { ejemplos de } \\
\text { necesidad de } \\
\text { prevención } \\
\text { cuaternaria en } \\
\text { EspañaDiagnostic } \\
\text { and therapeutic } \\
\text { activity } \\
\text { moderation. } \\
\text { Quaternary and } \\
\text { genetic } \\
\text { prevention }\end{array}$ & $\begin{array}{l}\text { Conceito de PQ aplicado } \\
\text { em situações de saúde } \\
\text { mais prevalentes }\end{array}$ & $\begin{array}{l}\text { O manuscrito discute a atividade } \\
\text { clínica como intervenção, a qual } \\
\text { deve ser de baixa intensidade e alta } \\
\text { qualidade, sem comprometer a } \\
\text { segurança do paciente. }\end{array}$ \\
\hline $\begin{array}{l}{ }^{34} \text { Prevención } \\
\text { cuaternaria em } \\
\text { ancianos }\end{array}$ & $\begin{array}{l}\text { PQ aplicada à população } \\
\text { idosa. }\end{array}$ & $\begin{array}{l}\text { O artigo discute o contexto de } \\
\text { morbidade e morte na atenção à } \\
\text { saúde do idoso, a necessidade de } \\
\text { evitarmos rastreios sem } \\
\text { embasamento científico e de propor } \\
\text { alternativas para as reabilitações, }\end{array}$ \\
\hline
\end{tabular}




\begin{tabular}{|c|c|c|}
\hline & & $\begin{array}{l}\text { que mantenham o máximo de uma } \\
\text { vida ativa. }\end{array}$ \\
\hline $\begin{array}{l}{ }^{37} \text { The four steps in } \\
\text { the prevention of } \\
\text { human } \\
\text { papillomavirus- } \\
\text { associated } \\
\text { neoplasia: } \\
\text { considerations for } \\
\text { preventive } \\
\text { measures, } \\
\text { screening, disease } \\
\text { impact, } \\
\text { potential and } \\
\text { overtreatments in } \\
\text { HPV-related } \\
\text { pathology }\end{array}$ & $\begin{array}{l}\text { A PQ analisada no } \\
\text { contexto da infecção por } \\
\text { HPV e os quatro passos } \\
\text { para sua prevenção. }\end{array}$ & $\begin{array}{l}\text { O artigo afirma que o uso } \\
\text { disseminado do teste do HPV, fora } \\
\text { das diretrizes publicadas, eleva as } \\
\text { possibilidades de que seja atribuído } \\
\text { a pacientes sadios, o rótulo de } \\
\text { doentes, causando desperdício de } \\
\text { tempo e gerando gastos } \\
\text { desnecessários, tanto para os } \\
\text { pacientes quanto para os serviços de } \\
\text { saúde. Além das repercussões } \\
\text { sociais de tal fato. }\end{array}$ \\
\hline $\begin{array}{l}{ }^{39} \text { Multimorbidity } \\
\text { and quaternary } \\
\text { prevention }\end{array}$ & $\begin{array}{l}\text { PQ e a assistência médica } \\
\text { centrada no paciente. }\end{array}$ & $\begin{array}{l}\text { O manuscrito discute a importância } \\
\text { de se considerar a experiência do } \\
\text { paciente com a doença e a } \\
\text { abordagem médica, sugerindo } \\
\text { políticas públicas direcionadas a } \\
\text { essa problemática. }\end{array}$ \\
\hline $\begin{array}{l}{ }^{47} \text { ¿ Overscreening } \\
\text { o prevención a } \\
\text { escala humana? } \\
\text { Tamizaje } \\
\text { excessivo }\end{array}$ & $\begin{array}{l}\text { Análise da PQ no cenário } \\
\text { da aplicação de métodos } \\
\text { de rastreio de forma } \\
\text { abusiva, excessiva ou } \\
\text { desnecessária }\end{array}$ & $\begin{array}{l}\text { Os autores reorientam a abordagem } \\
\text { da prevenção, redirecionando o } \\
\text { modelo preventivo da doença para o } \\
\text { indivíduo e organizando a prática } \\
\text { médica à luz do conceito de PQ. }\end{array}$ \\
\hline $\begin{array}{l}{ }^{35} \text { Prescrição } \\
\text { prudente } \quad \mathrm{e} \\
\text { desprescrição de } \\
\text { fármacos como } \\
\text { ferramentas para a }\end{array}$ & $\begin{array}{l}\text { Prescrição consciente e } \\
\text { desprescrição de fármacos } \\
\text { como ferramentas da PQ }\end{array}$ & $\begin{array}{l}\text { O manuscrito apresenta a } \\
\text { desprescrição e a prescrição } \\
\text { conscientes como ferramentas } \\
\text { fundamentais para se evitar a } \\
\text { sobremedicalização da população. }\end{array}$ \\
\hline
\end{tabular}




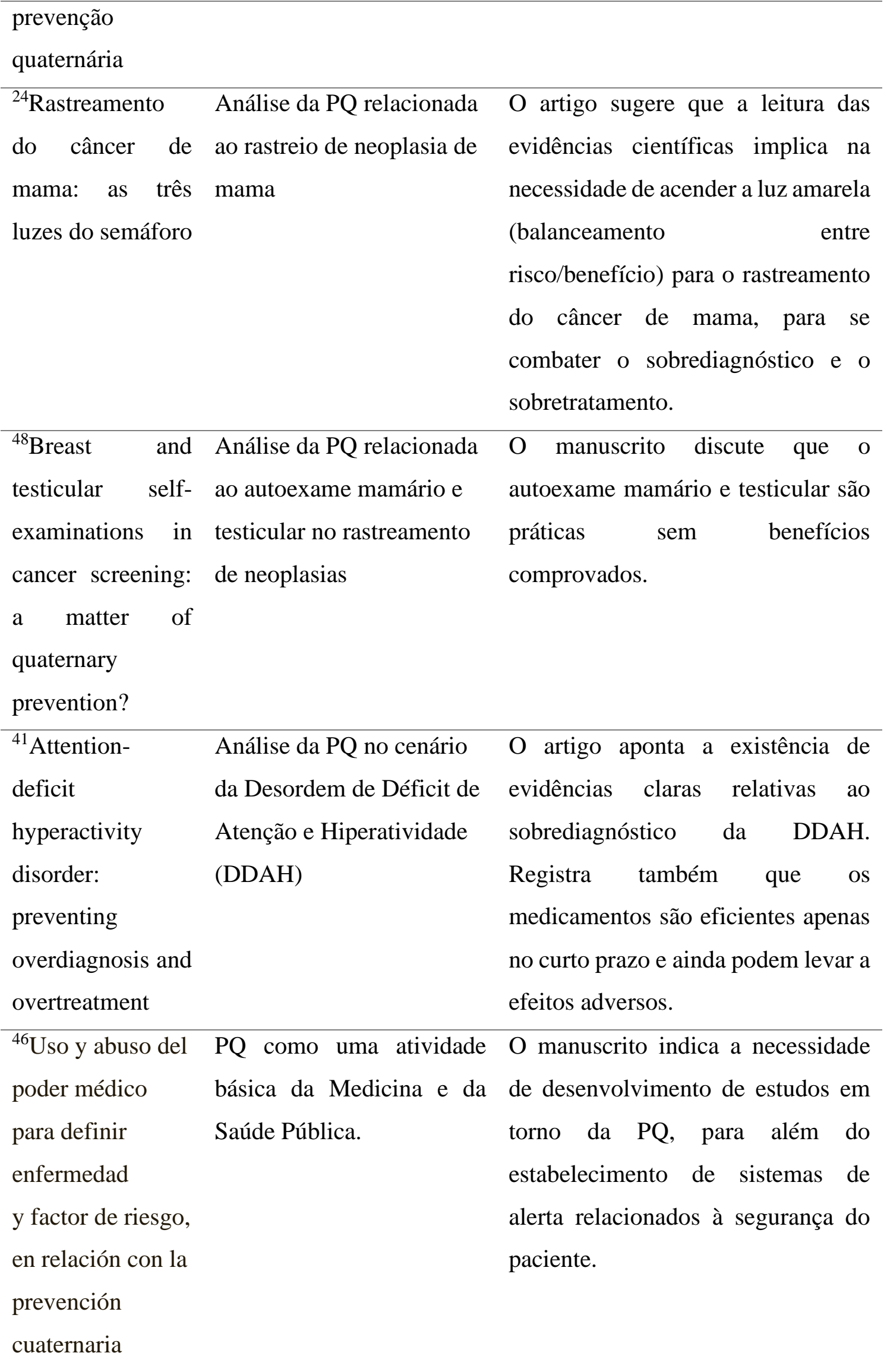




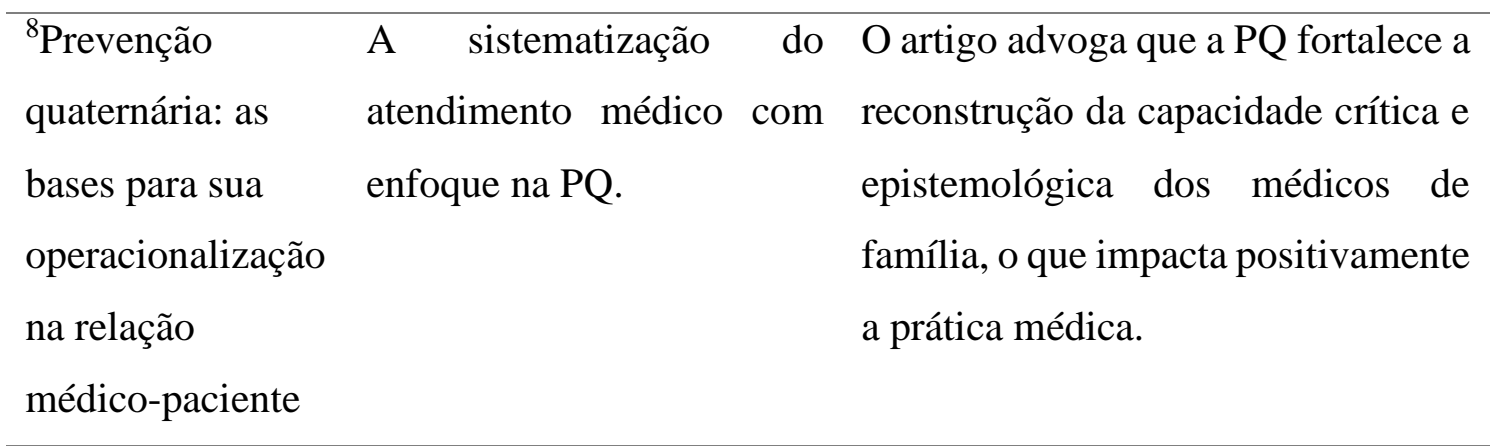
${ }^{29}$ Cuidado (!) na Análise da PQ no contexto O estudo realiza um comparativo prevenção do da medicalização social entre protocolos, fatores câncer: ética, que avança em direção a facilitadores e dificultadores da PQ, danos e uma suposta prevenção no Brasil e no Uruguai, equívocos problematizando a medicalização social. O autor aborda essa questão a partir dos protocolos de rastreio do câncer de mama, nesses países.

\begin{tabular}{lll}
\hline${ }^{28}$ Violência & Análise da violência & Os autores discutem a PQ frente à \\
obstétrica e & obstétrica e como a PQ & violência obstétrica, no Brasil. \\
prevenção & pode intervir nesta & Refletem que a PQ, neste cenário, \\
quaternária: o que & condição & requer o apoio de gestantes e \\
é e o que fazer & puérperas para a elaboração \\
& participativa de planos de parto e \\
& para que sejam atendidas as \\
& necessidades de humanização da \\
& assistência ao pré-natal e ao parto.
\end{tabular}

\begin{tabular}{lll}
\hline${ }^{25}$ Migraine & Análise da PQ relacionada & O manuscrito descreve a \\
treatment: a chain & à migrânea e os efeitos & importância da PQ no manejo da \\
of adverse effects & adversos de seus & migrânea. Mostra a pouca eficácia \\
& tratamentos & do uso de alguns fármacos e quais \\
& & seriam as opções mais indicadas para \\
& o tratamento deste agravo.
\end{tabular}

$\begin{array}{lll}{ }^{36} \text { Impact of } & \text { Conceituação de } & \text { Os autores propõem o } \\ \text { overdiagnosis and } & \text { sobrediagnóstico e } & \text { desenvolvimento de um olhar crítico } \\ \text { overtreatment on } & \text { sobretratamento, } & \text { do processo de trabalho, trazendo à } \\ \text { the patient, the } & \text { discutindo a aplicabilidade } & \text { tona as questões culturais da }\end{array}$




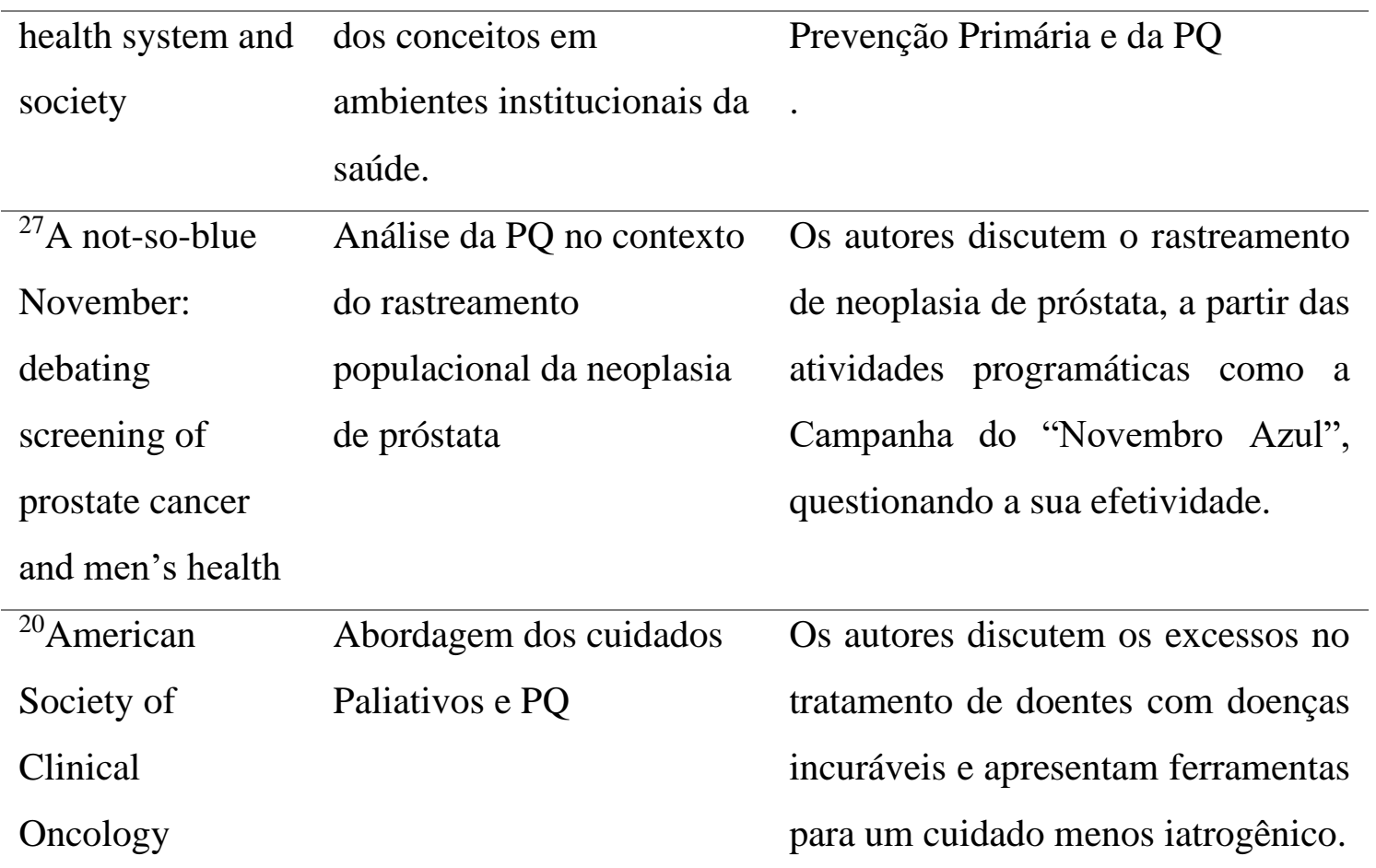

Provisional

Clinical Opinion:

The Integration of

Palliative Care

Into Standard

Oncology Care

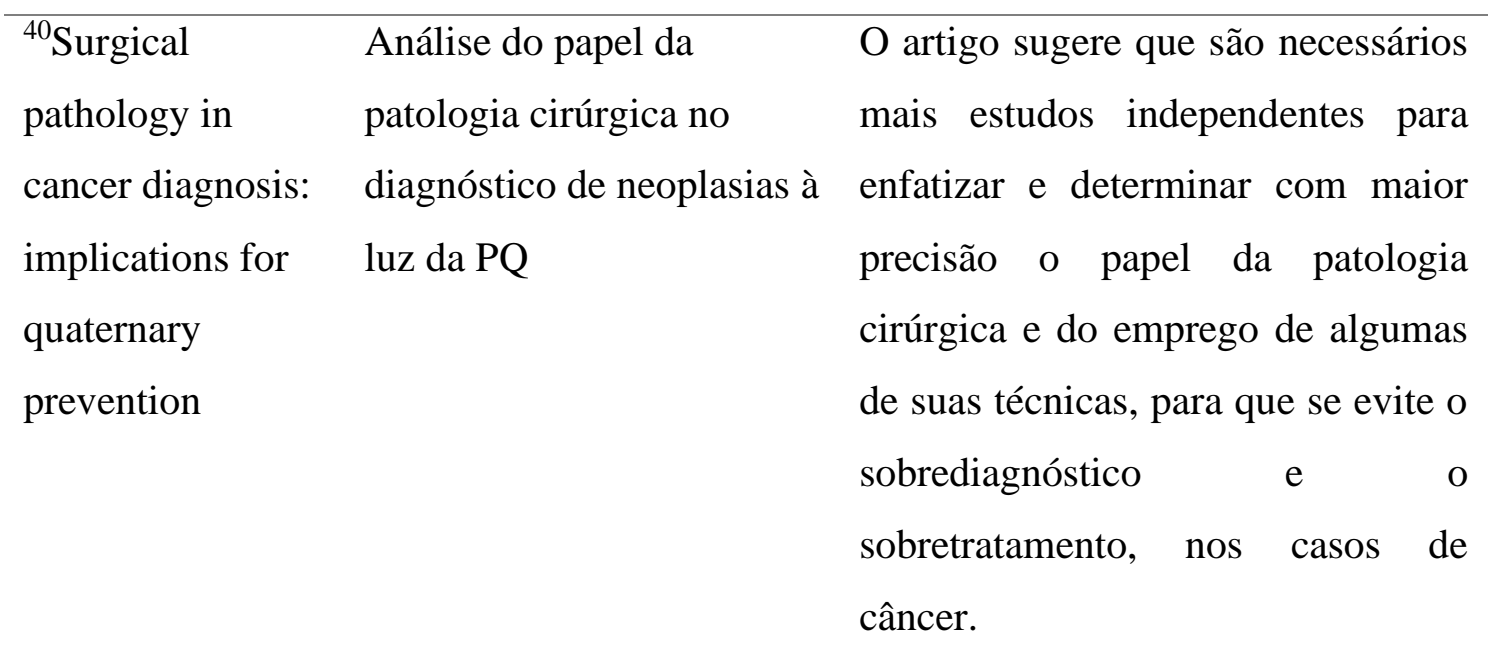

\begin{tabular}{lll}
${ }^{33}$ El enigma de la & A prática clínica na APS e & $\mathrm{O}$ manuscrito traz reflexões sobre \\
prevención & a PQ & intervenções comuns na prática \\
cuaternaria en & clínica, por meio de dois relatos de \\
atención primaria. & casos de pacientes com diversas \\
Cuándo hacer y & comorbidades, expostos à \\
\hline
\end{tabular}




\begin{tabular}{|c|c|c|}
\hline $\begin{array}{l}\text { cuándo no hacer } \\
\text { (a propósito de } 2 \\
\text { casos) }\end{array}$ & & $\begin{array}{l}\text { polifarmácia e aos seus danos em } \\
\text { potencial. }\end{array}$ \\
\hline $\begin{array}{l}{ }^{30} \text { Genética y } \\
\text { prevención } \\
\text { cuaternaria. El } \\
\text { ejemplo de la } \\
\text { hemocromatosis }\end{array}$ & $\begin{array}{l}\text { Discussão sobre rastreio } \\
\text { genético e PQ }\end{array}$ & $\begin{array}{l}\text { O autor discute o rastreio genético da } \\
\text { hemocromatose e a prevalência da } \\
\text { doença na população, além da } \\
\text { iatrogenia relacionada ao rastreio, } \\
\text { devido à baixa expressão fenotípica } \\
\text { da doença. }\end{array}$ \\
\hline $\begin{array}{l}{ }^{32} \text { Iatrogenia y } \\
\text { prevención } \\
\text { cuaternaria en } \\
\text { salud mental }\end{array}$ & $\begin{array}{l}\text { A PQ e a iatrogenia no } \\
\text { campo da saúde mental. }\end{array}$ & $\begin{array}{l}\text { O manuscrito expõe a importância } \\
\text { de colocar-se na balança aspectos } \\
\text { positivos e negativos dos } \\
\text { tratamentos, levando em } \\
\text { consideração sintomas e o contexto } \\
\text { no qual o paciente está inserido, } \\
\text { evitando-se } \\
\text { farmacológicas e psicoterapêuticas } \\
\text { excessivas. }\end{array}$ \\
\hline $\begin{array}{l}{ }^{42} \text { Impact of } \\
\text { quaternary } \\
\text { prevention as a } \\
\text { brief intervention } \\
\text { in medical } \\
\text { students' clinical } \\
\text { decisions: } \\
\text { experience from } \\
\text { Vietnam }\end{array}$ & $\begin{array}{l}\text { Avaliação do processo de } \\
\text { decisão de estudantes de } \\
\text { medicina após intervenção } \\
\text { sobre PQ }\end{array}$ & $\begin{array}{l}\text { Um total de } 115 \text { estudantes de } \\
\text { medicina do quinto ano participaram } \\
\text { do módulo do curso 'Triagem e } \\
\text { Prevenção para Indivíduo e Família'. } \\
\text { A introdução dessa discussão no } \\
\text { ensino médico mostrou auxiliar a } \\
\text { mudança da decisão clínica, } \\
\text { destacando a adoção da atenção } \\
\text { centrada no paciente, com o objetivo } \\
\text { de se evitar intervenções médicas } \\
\text { inadequadas. }\end{array}$ \\
\hline $\begin{array}{l}{ }^{44} \text { Medical } \\
\text { overuse and } \\
\text { quaternary } \\
\text { preventionin }\end{array}$ & $\begin{array}{l}\text { Estudo dos aspectos } \\
\text { relevantes que levam à } \\
\text { intervenção médica }\end{array}$ & $\begin{array}{l}\text { O estudo descreve os médicos de } \\
\text { família e comunidade como os } \\
\text { profissionais que frequentemente } \\
\text { estão localizados no ponto de partida }\end{array}$ \\
\hline
\end{tabular}




\begin{tabular}{|c|c|c|}
\hline $\begin{array}{l}\text { primary care-A } \\
\text { qualitative study } \\
\text { with general } \\
\text { practitioners }\end{array}$ & $\begin{array}{l}\text { excessiva e a importância } \\
\text { da PQ }\end{array}$ & $\begin{array}{l}\text { do processo de diagnóstico e de } \\
\text { tratamento. Destacam o potencial } \\
\text { desses profissionais no desempenho } \\
\text { da PQ. }\end{array}$ \\
\hline $\begin{array}{l}{ }^{23} \text { Prevention of } \\
\text { lipohypertrophy }\end{array}$ & $\begin{array}{l}\text { A abordagem à } \\
\text { lipohipertrofia com ações } \\
\text { de prevenção, incluindo a } \\
\text { PQ }\end{array}$ & $\begin{array}{l}\mathrm{O} \text { autor descreve a partir da } \\
\text { lipohipertrofia como se pode atuar } \\
\text { em cada nível de prevenção, } \\
\text { incluindo a PQ. }\end{array}$ \\
\hline $\begin{array}{l}{ }^{22} \text { Quaternary } \\
\text { prevention and } \\
\text { diabetes }\end{array}$ & $\begin{array}{l}\text { A abordagem do diabetes } \\
\text { mellitus considerando os } \\
\text { níveis de prevenção. }\end{array}$ & $\begin{array}{l}\mathrm{O} \text { estudo descreve a PQ como } \\
\text { atitude necessária para condução de } \\
\text { pacientes diabéticos, buscando } \\
\text { evitar a super medicalização. }\end{array}$ \\
\hline $\begin{array}{l}{ }^{49} \text { Vacunación } \\
\text { contra el virus del } \\
\text { papiloma humano } \\
\text { a la luz de la } \\
\text { prevención } \\
\text { cuaternaria }\end{array}$ & $\begin{array}{l}\text { Discussão sobre a } \\
\text { relevância da vacinação } \\
\text { em massa contra o HPV, } \\
\text { considerando a PQ. }\end{array}$ & $\begin{array}{l}\text { O artigo reforça a necessidade da } \\
\text { divulgação do conhecimento, em } \\
\text { uma ampla rede de informações, } \\
\text { para que os médicos de família e } \\
\text { comunidade possam discutir com } \\
\text { seus pacientes, individualmente, as } \\
\text { condutas mais indicadas para cada } \\
\text { caso. }\end{array}$ \\
\hline
\end{tabular}

Fonte: Produzido pelos autores, 2020. 


\section{DISCUSSÃO}

$\mathrm{Na}$ amostra estudada, o conceito de PQ elaborado por Jamoulle foi referenciado em seis $\operatorname{artigos}^{9}, 26,27,29,34,43$, dois ${ }^{31,47}$ empregaram o princípio de não-maleficência descrito por Hipócrates para discutir a PQ e os outros 22 artigos não apresentaram explicitamente o conceito de PQ.

A conceituação de PQ oriunda de Jamoulle permaneceu adormecida até o início dos anos 2000, quando começou a ser discutida por médicos de família, em várias partes do mundo, especialmente, pelo médico espanhol Juan Gérvas, autor de quatro artigos 9,30 , 31,34 dos seis identificados, nesta revisão, até 2012, destacando a necessidade de se evitar intervenções médicas desnecessárias e prejudiciais, como uma ação central dos médicos de família. Nos demais países, houve um aumento das publicações sobre PQ, a partir de 2012 e, particularmente, em 2015, registrou-se 40\% de todas as publicações encontradas, sendo o Brasil responsável pela publicação de $75 \%$ desses artigos. Esta expansão da discussão sobre PQ se relaciona aos eventos internacionais da WONCA, em 2010 e 2013, que trouxeram o conceito para luz da discussão, publicando documentos em mais de seis idiomas, ultrapassando fronteiras e alcançando novos territórios ${ }^{5}$.

Nesta revisão, discutiu-se as implicações da PQ para a prática clínica em diferentes situações: a revisão crítica do raciocínio clínico e da prática do médico de família; a atividade clínica e a segurança do paciente; o exercício da PQ nos serviços de urgência e emergência; a consideração na prática clínica da experiência da doença pelo paciente; a reorientação da aplicação de métodos de rastreio; a prescrição e a desprescrição conscientes de fármacos; a análise da medicalização social e de condições de morbidade em grupos populacionais e em condições de saúde específicos: ortopedia infantil, idosos, abordagem do HPV, DDAH, violência obstétrica e migrânea em crianças.

Devido a potencial gravidade dos diagnósticos e a necessidade de tomada de decisões rápidas, autores americanos ao avaliarem serviços de urgência/emergência, entenderam que as chances de ocorrerem condutas iatrogênicas nesses espaços era maior, o que justificaria a discussão acerca da PQ. Considerando que o gasto com tratamentos desnecessários, nos Estados Unidos, variou entre U\$158 e U\$226 bilhões, em 2011, e que o custo médio de um atendimento de emergência, nesse país, aumentou de US\$560 em 2003, para U\$1.354 em 2011, os autores destacaram a pertinência de se atuar na ótica da 
PQ, não só para se reduzir iatrogenias, mas também para se reduzir a ineficiência nos sistemas de saúde 21 .

O sobretratamento pode ocorrer quando um diagnóstico correto e oportuno é realizado, mas é iniciado um tratamento no qual o malefício é maior que o benefício para o paciente. Desta forma, propõe-se uma reflexão em relação aos efeitos do superdiagnóstico e do sobretratamento para os pacientes, para o sistema de saúde e para sociedade, em geral. Além disso, são enfatizadas propostas de atuação pautadas na PQ, destacando a importância da Atenção Primária em Saúde (APS) como um cenário imprescindível à redução das práticas iatrogênicas ${ }^{36}$.

A questão abordada em artigo produzido no Brasil foi o provável dano causado à sociedade pelos meios de comunicação, ao transmitirem aos cidadãos os temores relacionados a um diagnóstico negligenciado e suas consequências. Os autores comentaram que o deslumbramento em relação às tecnologias duras e às ações programáticas governamentais reforçavam a visão intervencionista e, consequentemente, aumentavam a probabilidade da ocorrência de ação iatrogênica ${ }^{39}$.

Estudo realizado com escolares, na Espanha, evidenciou que as solicitações de radiografias para crianças em idade escolar, por conta da presença de escoliose assintomática, não eram isentas de riscos, pois é conhecido que os raios-X substituem o íon cálcio pelo césio (radioativo), aumentando a incidência de tumores ósseos. Desta forma, os autores questionaram a real necessidade de investigação desses casos com exames complementares, além de abordarem questões sobre o tratamento sendo o paciente assintomático, o que poderia produzir mais dano do que benefício ${ }^{26}$.

O artigo procedente da Itália indicou que algo semelhante acontecia com as lesões de baixo grau, em citologias de mulheres infectadas pelo human papilomavirus (HPV). No tratamento de muitas lesões de HPV empregam-se estratégias de manejo ativo, para anormalidades citológicas de baixo grau de risco. Riscos associados a uma gravidez após a cirurgia cervical, possíveis complicações relacionadas às intervenções e aumento de custos foram exemplos de consequências danosas de tratamentos excessivos, sem qualquer evidência de benefício para as mulheres, individualmente ${ }^{37}$.

Por sua vez, pesquisa realizada na Espanha analisou como a prescrição de estatinas, de antidepressivos da classe dos inibidores seletivos de recaptação de serotonina e de inibidores da bomba de prótons aumentou nos últimos anos, na APS, sem que fosse observada uma diminuição da morbimortalidade ${ }^{31}$. 
A medicalização de fatores de risco é uma questão que ultrapassa a associação estatística de elevação da probabilidade da ocorrência da doença e gera uma associação de causalidade, medo e uso inapropriados de medicamentos ${ }^{11}$. Houve consenso entre diferentes autores, quando analisaram a medicalização de fatores de risco, colocando a PQ como uma atividade essencial da Medicina e da Saúde Pública. Ademais, ressaltaram a necessidade de desenvolvimento de estudos mais abrangentes sobre a prática da PQ, extrapolando aqueles que ressaltam o estabelecimento de sistemas de alerta de segurança do paciente ${ }^{9,11}$.

Da mesma forma, autores brasileiros discutiram que a medicalização pode levar à polifarmácia, isto é, o paciente que faz uso de cinco ou mais medicamentos. Os pesquisadores recomendaram a reconsideração da prescrição desde a anamnese, do exame físico até o diagnóstico, para se avaliar a real indicação de uso do fármaco ${ }^{35}$. Salientaram ainda a necessidade de os médicos exercitarem a desprescrição e a prescrição conscientes, reconhecendo-as como ferramentas fundamentais para se evitar a sobremedicalização da população ${ }^{35}$.

Os aspectos teóricos e práticos da consulta médica associados à atuação ética profissional também foram explorados, no sentido de se preservar a segurança do paciente e facilitar a construção conjunta de condutas. O manejo das expectativas, as ideias e percepções dos pacientes sobre o adoecimento, diferenciando o sofrimento presente daquele do futuro e o uso da demora permitida foram caracterizados como aspectos favoráveis ao exercício da $\mathrm{PQ}^{8}$.

Estudos provenientes da Bélgica e da Espanha apresentaram a discussão acerca da maior exposição do médico de família às doenças crônicas não transmissíveis, as quais são geralmente controláveis e não curáveis, decorrentes da transição epidemiológica e demográfica, observada desde a década de 1970. Essa realidade permite ao médico de família exercer mais rotineiramente a PQ em função da singularidade da organização da prática médica na APS, onde há a possibilidade de se personalizar o uso de testes de triagem para as doenças crônicas não transmissíveis, buscando as características individuais, ao invés de se basear apenas em diretrizes gerais ${ }^{43}$. Ainda, problematizou-se o cenário de morbidade e morte, especificamente, na atenção à saúde ao idoso ${ }^{34}$.

Estudo brasileiro ao discutir os testes de rastreio, isto é, aqueles realizados em uma população assintomática, objetivando o diagnóstico precoce de determinadas doenças, reafirma a possibilidade de seus resultados serem verdadeiros ou falsos. Por sua 
vez, se houver a clara compreensão, por parte do paciente dessas condições, se reduz a probabilidade do surgimento de um problema entre o médico e o paciente, no momento da comunicação do resultado dos testes ${ }^{47}$. Isso implica reconhecer que o bom relacionamento médico-paciente representa um terreno fértil para o desenvolvimento da PQ, principalmente, em situações controversas da prática médica.

Um exemplo claro de rastreio controverso é aquele relacionado ao câncer de próstata. No estudo denominado European Randomized Study of Screening for Prostate Cancer randomizou-se 182.160 homens, em nove países, a partir das variáveis faixa etária, ponto de corte do PSA para indicar biópsia e frequência do rastreio. A frequência de realização de testes para detectar sinais de doença variou entre 2 e 7 anos, os níveis de PSA entre 2,5 e $10 \mathrm{ng} / \mathrm{ml}$ e a faixa etária de 55 anos a 69 anos. Após 13 anos de acompanhamento observou-se apenas a redução absoluta de 0,11 mortes por câncer de próstata, para cada mil homens submetidos aos procedimentos de detecção precoce ${ }^{41}$. Esses dados reforçaram a não recomendação do rastreio de neoplasia de próstata como uma medida de PQ.

A Força-Tarefa de Saúde Preventiva dos EUA analisou sete ensaios clínicos, randomizados e controlados (total de 600 mil mulheres) comparando a taxa de mortalidade de um grupo de mulheres com idade entre 39 e 74 anos submetidas à mamografia de rastreamento, com a taxa de um grupo de mulheres não submetidas ao exame, após 13 anos. O risco relativo foi de 0,85 (0,75-0,96) para mulheres com idade entre 39 e 49 anos, 0,86 (0,75-0,99) para as mulheres com idade entre 50 e 59 anos e de 0,68 $(0,54-0,87)$ para aquelas na faixa etária entre 60 e 69 anos. Em decorrência desse estudo a referida instituição recomendou o rastreamento do câncer de mama com mamografia bianual (nível de evidência B) para mulheres com idades entre 50 e $69 \operatorname{anos}^{27}$. A mamografia conduz a uma maior taxa de detecção de cânceres que crescem de forma lenta, sobretudo o carcinoma in situ. Nota-se que esse método de rastreamento apresenta um percentual de detecção desse tipo de câncer estimado entre 19\% a 30\%. Nesta perspectiva, pesquisadores do The Nordic Cochrane Centre fizeram um alerta relativo à adoção deste tipo de conduta quando estimaram que o rastreamento regular, por 10 anos, de 2 mil mulheres, indicaria para dez mulheres saudáveis, o diagnóstico de câncer de mama que nunca comprometeria a qualidade de vida, mas em contrapartida, poderia acarretar em intervenções invasivas e comprometimento psicológico ${ }^{24}$. 
Em estudo brasileiro, o autor ao discutir a indicação de rastreio de câncer de mama, conclamou os médicos de família e as autoridades de saúde para a revisão de protocolo que pode causar danos às mulheres e sobre a premência de disseminação de informação baseada em evidência, com a produção de orientações compreensíveis que contribuam com o compartilhamento de decisões entre os médicos e as suas pacientes ${ }^{29}$.

O estudo português compilou considerações referentes ao autoexame mamário e testicular, nos rastreamentos oncológicos, registrando a ausência de evidências de que o autoexame, diminuiria a morbimortalidade da população ${ }^{48}$

De outro modo, pesquisa canadense estimou que uma em cada cinco crianças foi diagnosticada com Transtorno de Déficit de Atenção e Hiperatividade (TDAH), em Kentucky, EUA. Nas duas últimas décadas, a incidência de TDAH aumentou, especialmente, nos EUA, com um acréscimo de dez vezes, no uso de medicamentos. O mercado de medicamentos anti-TDAH passou de US\$ 15 milhões, em meados dos anos 90, para US\$ 9 bilhões, em 2012. A consequência desses diagnósticos foi o surgimento de indivíduos polimedicados, com resultados potencialmente desastrosos. Em 2010, uma pesquisa com 325 participantes indicou que $48 \%$ dos pacientes diagnosticados com TDAH relataram pelo menos um efeito colateral com o uso dos medicamentos indicados para tratar essa doença, como alteração do apetite, insônia e variação do humor. Além disso, as drogas anti-TDAH mostraram-se pouco eficazes, em longo prazo, e o uso concorreu com eventos adversos importantes ${ }^{41}$

Observou-se situação semelhante no tratamento de migrânea em crianças, no estudo português denominado Migraine treatment: a chain of adverse effects, de 2015. Verificou-se que o uso em larga escala de acetaminofeno, um medicamento com baixo poder abortivo nas crises de migrânea, expôs os pacientes aos efeitos adversos indesejados desse fármaco, ratificando a importância da PQ no manejo da migrânea em crianças $^{25}$.

Importante destacar o estudo brasileiro que analisou o exercício da PQ relacionada à violência obstétrica, definida como qualquer forma de dano originado no cuidado obstétrico profissional. A violência obstétrica atingiu $25 \%$ das mulheres que necessitaram dessa atenção, destacando-se o alto número de cesáreas (55,6\% do total de nascimentos no Brasil) e intervenções desnecessárias (venóclise, ocitocina de rotina e episiotomia) ${ }^{29}$. Interessante notar que de acordo com documento publicado pela OMS, a taxa de cesáreas desejável é em torno de $10 \%^{50}$. Assim, os autores provocaram a reflexão da potência do 
exercício da PQ no cenário obstétrico, mas alertaram que essa prática requer o apoio das gestantes na elaboração participativa dos planos de parto, no sentido de serem executadas práticas humanizadas de assistência ao pré-natal e ao parto ${ }^{28}$.

A análise da abordagem dos cuidados paliativos pontuou os excessos no tratamento de pacientes com doenças incuráveis e apresentou ferramentas para um cuidado menos iatrogênico, ou seja, indicou a prática da PQ para essa população. Vale assinalar que a OMS recomenda uma abordagem integrada de cuidados paliativos no tratamento de pacientes com câncer que se caracteriza por suporte psicossocial, manejo dos sintomas e plano de cuidado ${ }^{20}$.

Estudo brasileiro reforçou o diálogo entre o médico de família e o patologista, como forma de exercício da PQ, a fim de que alterações nos exames de anatomia patológica derivados de várias técnicas, não sejam avaliadas de modo desconexo do quadro clínico do paciente, pois isso poderia acarretar no aumento de cuidados desnecessários $^{40}$. O estudo incentivou o médico de família a discutir os casos oncológicos com o médico patologista, na perspectiva do conceito de PQ, para que sejam evitados o sobrediagnóstico e o sobretratamento cirúrgico ${ }^{40}$.

Os principais achados de um estudo brasileiro apontaram que a utilização adequada dos recursos disponíveis para a saúde, com indicações claras baseadas em evidências científicas, é necessária para a manutenção dos serviços, favorecendo a qualidade do cuidado ofertado, além de reforçar a importância de um relacionamento médico-paciente robusto e transparente, como fundamento para o exercício da $\mathrm{PQ}^{8}$.

O relato de dois casos clínicos descreveu intervenções realizadas em pacientes idosos, com multimorbidades e uso de diversos medicamentos, os quais sofreram com doenças adicionais secundárias às terapêuticas adotadas. Assim, recomendou-se a necessidade de se balancear os fatores positivos e negativos para definição da conduta a ser tomada, principalmente, quando a população for idosa ${ }^{33}$.

Autores espanhóis expuseram a dificuldade em realizar a PQ baseada em fatores genéticos, porque muitas vezes, as descobertas no campo da genética propiciam uma falsa impressão de domínio sobre as doenças. O estudo enfatizou que nem sempre identificar o genótipo determina o fenótipo patológico ${ }^{30}$.

O compilado trazido em artigo também da Espanha alertou para a produção de cuidados relacionados aos transtornos mentais e seus possíveis efeitos iatrogênicos, descrevendo situações onde a intervenção farmacológica e psicoterapêutica mostraram- 
se mais danosas do que benéficas, ratificando a PQ como fator essencial para o cuidado integral na saúde mental ${ }^{32}$.

O estudo produzido no Vietnan avaliou as tomadas de decisões de estudantes vietnamitas após uma intervenção breve sobre PQ. Os estudantes do quinto ano de medicina foram submetidos a três situações clínicas antes e depois da intervenção. A análise das condutas propostas pelos mesmos estudantes evidenciou uma mudança de pensamento, principalmente, relacionada à prevenção primária e quaternária, com a diminuição da proposição de ações desnecessárias ${ }^{42}$.

O objetivo do estudo procedente da Alemanha foi obter uma compreensão profunda dos fatores mais importantes que levam a condutas excessivas na prática médica. O grupo de médicos de família da Bavária, respondeu a uma entrevista semiestruturada e após análise das respostas, os resultados mostraram uma dificuldade no manejo dos pacientes, pois os mesmos tinham livre acesso à atenção secundária, levando ao tratamento médico especializado, sem uma indicação precisa. Além disso, na percepção dos participantes da pesquisa havia uma má aceitação pela comunidade do fato de a APS ser a porta de entrada do sistema de saúde. A proposta de mudança compreendeu o investimento na educação médica, o desenvolvimento da relação médico-paciente confiável, a melhoria das estruturas da APS e o envolvimento dos pacientes e da sociedade na definição das condutas clínicas, na visão dos entrevistados ${ }^{44}$.

O estudo indiano com enfoque na lipodistrofia descreveu ações relacionadas aos níveis de prevenção primária, secundária, terciária e quaternária. Destacou também que o diagnóstico é essencialmente clínico, devendo-se evitar a solicitação de exames (como o ultrassom) e o excesso nas prescrições de injetáveis, reafirmando o uso da PQ como um instrumento para a redução de condutas que levam a danos aos pacientes com esta condição ${ }^{23}$.

Pontua-se que uma limitação deste estudo pode estar relacionada à quantidade reduzida de artigos publicados sobre a temática, o que impossibilitou a elaboração de mais de uma estratégia de busca de evidência, em função da pergunta de pesquisa. 


\section{CONCLUSÃO}

As evidências analisadas recomendaram o fortalecimento da relação médicopaciente para à construção de cuidados menos iatrogênicos. Os artigos trazidos tratam de ações na área de saúde da criança, saúde da mulher e do idoso, além de doenças específicas como a hemocromatose. Da mesma forma, os estudos analisados ratificaram a complexidade do processo saúde-doença e o fato de sua análise apenas no campo do modelo biomédico dificultar o exercício da $\mathrm{PQ}$, pois minimizam a importância dos determinantes sociais de saúde e dos fatores culturais na produção do adoecimento.

Os resultados do estudo provocam a comunidade médica e, em especial, a de médicos de família, a refletir sobre a incorporação de uma prática médica menos iatrogênica, valorizando a medicina centrada na pessoa e nos atributos da APS. Reafirmam ainda que as condutas clínicas devem ser cada vez mais individualizadas, considerando não apenas os protocolos e as diretrizes, mas também a junção das expectativas do paciente com a história natural da doença. Ficou patente que a relação médico-paciente robusta e a longitudinalidade do cuidado constituem-se condições facilitadoras para o exercício de práticas clínicas menos intervencionistas, minimizando intervenções pouco efetivas, geradoras de risco para o paciente e de custo elevado para o sistema de saúde.

Acredita-se que a principal contribuição desse trabalho, ao apresentar uma síntese das evidências de PQ para a prática clínica, seja despertar a comunidade científica para a importância da atuação do médico de família, no fortalecimento do exercício da PQ, o que repercutirá em ganhos assistenciais diretos para o paciente e para a gestão dos sistemas de saúde. 


\section{RECOMENDAÇÕES PRÁTICAS SOBRE PQ PARA OS MÉDICOS DA ATENÇÃo PRIMÁRIA À SAÚdE}

As recomendações compiladas abaixo são fruto da análise do material compilado para produção da dissertação: "Prevenção quaternária e suas implicações para a prática clínica: uma revisão sistemática”. O objetivo é fornecer um guia de fácil manejo para os médicos da Atenção Primária em Saúde, e contribuir para que sejam trilhados caminhos menos iatrogênicos, mais seguros e eficientes na prática clínica cotidiana.

\section{RECOMENDAÇÕES}

\section{Saúde do Adulto}

1) Aplicar testes de triagem baseados em protocolos científicos, com atenção as questões individuais de cada paciente.

2) Evitar o uso disseminado do teste do HPV, fora das diretrizes publicadas.

3) O autoexame testicular não deve ser realizado pois não tem benefício estabelecido.

4) No manejo da migrânea, atentar para a pouca eficácia do uso de alguns fármacos, como o acetaminofeno, e quais seriam as opções mais adequadas para o tratamento levando em consideração a faixa etária do paciente e frequência das crises.

5) Rastrear neoplasia de próstata, apenas em pacientes que apresentam fatores de risco e sintomas correlacionados.

6) Considerar aspectos positivos e negativos dos tratamentos propostos para transtornos mentais, evitando-se intervenções farmacológicas e psicoterapêuticas excessivas.

\section{Saúde da Criança}

1) Não utilizar exames complementares para avaliação de crianças assintomáticas portadoras de escoliose.

2) Prescrever com cautela terapia medicamentosa para Desordem de Déficit de Atenção e Hiperatividade (DDAH), tendo em vista a eficácia a curto prazo da 
terapia medicamentosa e a incidência de efeitos adversos, como morte súbita, ideação suicida, agressões e dor no peito.

\section{Saúde do Idoso}

1) Evitar rastreios sem embasamento científico, propor alternativas para as reabilitações, que mantenham o máximo de uma vida ativa.

2) A desprescrição e a prescrição conscientes são ferramentas fundamentais para se evitar a sobremedicalização da população.

3) Os excessos no tratamento de doentes com doenças incuráveis devem ser avaliados e propostas ferramentas para um cuidado menos iatrogênico, como o uso de aplicativos que fornecem conteúdos educativos para facilitar o manejo e controle da dor (Educador).

\section{Saúde da Mulher}

1) É necessário avaliar com cautela o rastreamento do câncer de mama, ponderando riscos e benefícios para cada paciente.

2) O autoexame mamário não deve ser realizado por ser uma prática sem benefício comprovado.

3) Apoiar gestantes e puérperas, oferecendo informações e compartilhando decisões, para a elaboração participativa de planos de parto e para que sejam atendidas as necessidades de humanização da assistência ao pré-natal e ao parto. 


\section{CONSIDERAÇÕES FINAIS SOBRE A DISSERTAÇÃO}

O estudo da PQ é necessário para diminuirmos a morbimortalidade secundária aos cuidados iatrogênicos e para utilização adequada dos recursos destinados a área da saúde, pois são finitos. A discussão de tal tema deve ser estimulada na graduação, construindo um raciocínio clínico menos danoso.

Os resultados do estudo ratificaram que o uso da PQ na prática clínica, leva a um cuidado menos iatrogênico, principalmente, no cenário da APS, com a atuação de seu especialista, o Médico de Família e Comunidade, apoiada na Método Clínico Centrado na Pessoa e na operacionalização de seus atributos.

A análise das evidências científicas atuais produzidas sobre o objeto de investigação, aliada ao conhecimento dos aspectos biopsicossociais que envolvem o paciente, certamente facilitam a utilização da PQ como estratégia de circunspecção.

Da mesma forma, o estudo destacou que se faz necessária a construção sólida da relação médico-paciente para que a PQ possa ser desenvolvida. Nesta perspectiva, a longitudinalidade do cuidado, atributo essencial da APS, se apresenta como um agente facilitador desse processo de construção conjunta entre profissional e paciente do projeto terapêutico.

Além disso, destaca-se que os aspectos culturais, históricos assim como os demais determinantes sociais da saúde devem ser conhecidos e respeitados para adequação das condutas terapêuticas menos iatrogênicas e mais individualizadas, favorecendo o uso racional de recursos do sistema de saúde. Em síntese, nota-se que o saber mais aprofundado sobre as características do processo saúde-doença-cuidado pode auxiliar sobremaneira no desenvolvimento de uma prática médica centrada no paciente e com potencial para colaborar na redução das iniquidades em saúde. 


\section{REFERÊNCIAS BIBLIOGRÁFICAS}

1. Declaration of Alma-Ata International Conference on Primary Health Care. AlmaAta 1978 USSR.

2. Washington DC. Informe Dawson sobre el futuro de los servicios medicos y afines. Paho Coll: Organización Panamericana de la Salud; 1968. p. 38.

3. Criação do CSE P, SUS . [Available from: https://unasus2.moodle.ufsc.br/pluginfile.php/6109/mod_resource/content/1/Conteudo_ on-line_2403/un01/obj2.html.

4. Brasil. Página 68 da seção 1 do diário oficial da União (DOU). PORTARIA No 2.435, de 21 de setembro de 2017. ed22 de Setembro de 2017.

5. Soratto J, de Pires D, Dornelles S, Lorenzetti J. Family health strategy: a technological innovation in health. Texto \& Contexto - Enfermagem [online]. 2015. p. 584-92.

6. Brasil. Ministério da Saúde 2020 [Available from: https://egestorab.saude.gov.br/paginas/acessoPublico/relatorios/relHistoricoCoberturaA B.xhtml.

7. Bentzen N. Wonca Dictionary of General. Family Practice. 2004.

8. Norman AH, Tesser CD. Prevenção quaternária: as bases para sua operacionalização na relação médico-paciente. Revista Brasileira de Medicina de Família e Comunidade. 2015;10(35):1-10.

9. Gérvas J, Pérez Fernández M. [Limits to the power of medicine to define disease and risk factor, and quarternary prevention]. Gac Sanit. 2006;20 Suppl 3:66-71.

10. Gérvas J, Pérez MF. Genetics and quaternary prevention. The example of haemochromatosis. Atencion primaria. 2003;32(3):158-62. 
11. Norman AH, Tesser CD. [Quaternary prevention in primary care: a necessity for the Brazilian Unified National Health System]. Cad Saude Publica. 2009;25(9):2012-20.

12. Colão CdF. Saúde do homem: conhecimento sobre o rastreamento do câncer de próstata por profissionais da Estratégia de Saúde da Família na Zona Oeste do Rio de Janeiro. 2015.

13. Martins C, Godycki-Cwirko M, Heleno B, Brodersen J. Quaternary prevention: reviewing the concept: Quaternary prevention aims to protect patients from medical harm. European Journal of General Practice. 2018;24(1):106-11.

14. CD T, AH N. Prevenção quaternária e práticas integrativas e complementares em saúde (I): aproximação fundamental.: Rev Bras Med Fam Comunidade; 2020

15. Melo NAd, Fernandes D, Assis Ld, Pinheiro MdL, Carvalho A, Morais M. Quaternary prevention and the prescription of Chloroquine and Hydroxychloroquine in COVID-19: are they worth the risk? Rev Bras Med Fam Comunidade 2021.

16. Berwanger O, Suzumura EA, Buehler AM, Oliveira JB. Como avaliar criticamente revisões sistemáticas e metanálises?2007; 9:[475 - 80 pp.]. Available from: https://doi.org/10.1590/S0103-507X2007000400012.

17. Guanilo MlT, Takahashi R, Bertolozzi M. Revisão sistemática: noções gerais. . Revista da Escola de Enfermagem da USP.2011. p. 1260-6. .

18. Sampaio RF, Mancini MC. "Systematic review studies: a guide for careful synthesis of the scientific evidence." Brazilian Journal of Physical Therapy 2007. p. 839

19. Ouzzani M, Hammady H, Fedorowicz Z, Elmagarmid A. Rayyan-a web and mobile app for systematic reviews. Syst Rev. 2016;5(1):210. 
20. Smith TJ, Temin S, Alesi ER, Abernethy AP, Balboni TA, Basch EM, et al. American Society of Clinical Oncology provisional clinical opinion: the integration of palliative care into standard oncology care. J Clin Oncol. 2012;30(8):880-7.

21. Carpenter CR, Raja AS, Brown MD. Overtesting and the downstream consequences of overtreatment: implications of "preventing overdiagnosis" for emergency medicine. Academic Emergency Medicine. 2015;22(12):1484-92.

22. Kalra S, Sreedevi A, Unnikrishnan AG. Quaternary prevention and diabetes. J Pak Med Assoc. 2014;64(11):1324-6.

23. Kalra S, Kumar A, Gupta Y. Prevention of lipohypertrophy. J Pak Med Assoc. 2016;66(7):910-1.

24. Santos JA. Rastreamento do câncer de mama: as três luzes do semáforo. Revista Brasileira de Medicina de Família e Comunidade. 2013;8(26):11-5.

25. Veloso TS, Cambão MS. Migraine treatment: a chain of adverse effects. Springerplus. 2015;4:409.

26. Cruz-Tabuenca H. Sobre la prevención cuaternaria en niños escolares. Medicina Naturista. 2015;9(2).

27. Modesto AADA, Lima RLBd, D'Angelis AC, Augusto DK. A not-so-blue November: debating screening of prostate cancer and men's health. InterfaceComunicação, Saúde, Educação. 2018;22(64):251-62.

28. Tesser CD, Knobel R, de Aguiar Andrezzo HF, Diniz SG. Violência obstétrica e prevenção quaternária: o que é e o que fazer. Revista Brasileira de Medicina de Família e Comunidade. 2015;10(35):1-12.

29. Tesser CD. Cuidado (!) na prevenção do câncer: ética, danos e equívocos. Revista Brasileira de Medicina de Família e Comunidade. 2014;9(31):180-2. 
30. Gérvas J, Pérez Fernández M. Genética y prevención cuaternaria. El ejemplo de la hemocromatosis. Atención Primaria2003. p. 158-62.

31. Gérvas J. Moderación en la actividad médica preventiva y curativa. Cuatro ejemplos de necesidad de prevención cuaternaria en España. Gaceta sanitaria. 2006;20:127-34.

32. Ortiz Lobo A, Ibáñez Rojo V. Iatrogenia y prevención cuaternaria en salud mental. Revista Española de Salud Pública. 2011;85(6):513-25.

33. Cucalón JM, Guiu M. The enigma of quaternary prevention in Primary Care. When and when not to do it (presentation of two cases). Semergen. 2013;39(6):313-5.

34. Gérvas J. [Quaternary prevention in the elderly]. Rev Esp Geriatr Gerontol. 2012;47(6):266-9.

35. Santana MdCG, Gavilán-Moral E, Villafaina-Barroso A, Jiménez-de Gracia L. Prescripción prudente y deprescripción de fármacos como herramientas para la prevención cuaternaria. Revista Brasileira de Medicina de Família e Comunidade. 2015;10(35):1-8.

36. Coll-Benejam T, Bravo-Toledo R, Marcos-Calvo MP, Astier-Peña MP. [Impact of overdiagnosis and overtreatment on the patient, the health system and society]. Aten Primaria. 2018;50 Suppl 2:86-95.

37. Liverani CA. The four steps in the prevention of human papillomavirus-associated neoplasia: considerations for preventive measures, screening, disease impact, and potential overtreatments in HPV-related pathology. Arch Gynecol Obstet. 2013;288(5):979-88.

38. Baricević IZ, Botica MV, Renar IP. [Quaternary prevention as a basis for rational approach to the patient in family practice]. Lijec Vjesn. 2014;136(5-6):152-5. 
39. Mangin D, Heath I. Multimorbidity and quaternary prevention (P4). Revista Brasileira de Medicina de Família e Comunidade. 2015;10(35):1-5.

40. Yver M. Surgical pathology in cancer diagnosis: implications for quaternary prevention. Revista Brasileira de Medicina de Família e Comunidade. 2015;10(35):1-7.

41. St-Onge J-C. Attention-deficit hyperactivity disorder: preventing overdiagnosis and overtreatment. Revista Brasileira de Medicina de Família e Comunidade. 2015;10(35):1-8.

42. Tran THV, Vo TL. Impact of quaternary prevention as a brief intervention in medical students' clinical decisions: experience from Vietnam. Revista Brasileira de Medicina de Família e Comunidade. 2015;10(35):1-8.

43. Bae J-M, Jamoulle M. Primary care physicians' action plans for responding to results of screening tests based on the concept of quaternary prevention. Journal of Preventive Medicine and Public Health. 2016;49(6):343.

44. Alber K, Kuehlein T, Schedlbauer A, Schaffer S. Medical overuse and quaternary prevention in primary care - A qualitative study with general practitioners. BMC Fam Pract. 2017;18(1):99.

45. Ebell MH, Siwek J, Weiss BD, Woolf SH, Susman J, Ewigman B, et al. Strength of recommendation taxonomy (SORT): a patient-centered approach to grading evidence in the medical literature. Am Fam Physician. 2004;69(3):548-56.

46. Gérvas J, Fernández MP. Uso y abuso del poder médico para definir enfermedad y factor de riesgo, en relación con la prevención cuaternaria. Gaceta Sanitaria. 2006;20:66-71.

47. Bàez MP. ¿Overscreening o prevención a escala humana? Tamizaje excesivo. Revista Brasileira de Medicina de Família e Comunidade2015. p. 1-7. 
48. Santos JA. Autoexames mamário e testicular nos rastreamentos oncológicos: uma questão de prevenção quaternária? Revista Brasileira de Medicina de Família e Comunidade. 2015;10(36).

49. Pizzanelli M, Jamoulle M. Vaccination against human papilloma virus in the light of quaternary prevention. Revista Brasileira de Medicina de Família e Comunidade. 2019;14(41):1800.

50. Organização Mundial da Saúde. Declaração da OMS sobre Taxas de Cesáreas. 2015. 
ANEXO

ANEXO A - Aprovação do CEP

\section{USP - CENTRO DE SAÚDE \\ ESCOLA DA FACULDADE DE \\ MEDICINA DE RIBEIRÃO}

\section{PARECER CONSUBSTANCIADO DO CEP}

\section{DADOS DO PROJETO DE PESQUISA}

Titulo da Pesquisa: Conhecimentos dos médicos da atenção primária à saúde acerca da prevenção quaternária: estudo transversal

Pesquisador: Janise Braga Barros Ferreira

Área Temática:

Versão: 2

CAAE: 01841218.6 .0000 .5414

Instituição Proponente: Centro de Saúde Escola da Faculdade de Medicina de Ribeirão Preto - USP

Patrocinador Principal: Financiamento Próprio

\section{DADOS DO PARECER}

Número do Parecer: 3.132 .660

\section{Apresentação do Projeto:}

O presente projeto objetiva identificar o conhecimento sobre prevenção quaternária (PQ) entre os médicos que atuam na atenção primária à saúde (APS) em todo o Brasil, sejam eles médicos de família e comunidade ou de outras especialidades. A PQ é o conjunto de açôes que visam evitar danos associados às intervenções médicas e de outros profissionais da saúde como excesso de medicação ou cirurgias desnecessárias; ela pode ser definida também como "a deteç̧ão de individuos em risco de tratamento excessivo, para protegê-los de novas intervençōes médicas inapropriadas e sugerir-lhes altemativas eticamente aceitáveis". Para alcançar tal propósito, os pesquisadores utilizar-se-âo de uma entrevista autopreenchida que será enviada "on line" e que usará a escala de Likert. Antes do instrumento (entrevista) ser aplicado aos participantes da pesquisa, ele será validado por dois "juizes", isto é, médicos com competência na área estudada. Os juizes serão escolhidos "por meio de pesquisa de publicaçōes/atuaçóes e conhecimento das pesquisadoras desses profissionais".

\section{Objetivo da Pesquisa:}

Objetivo Geral:

1) Identificar o conhecimento dos médicos da atenção primária à saúde acerca da $P Q$ :

Objetivos Especificos

\begin{tabular}{|c|c|c|c|c|}
\hline Bairro: & SUMAREZINHO & & CEP: $14.055-380$ & \\
\hline UF: SP & Municipio: & RIBEIRAO PRETO & & \\
\hline Telefon: & $(16) 3315-0009$ & & E-mail: & csecuiaba@imp.usp.bx \\
\hline
\end{tabular}




\section{USP - CENTRO DE SAÚDE \\ ESCOLA DA FACULDADE DE MEDICINA DE RIBEIRÃO

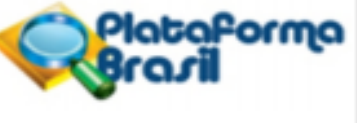

Corkinuaça do Precer: 3.132660

1) Caracterizar o perfil dos médicos segundo sexo, idade, ano de conclusão da graduação, ano de término da especialização (residência médica), ano de titulação de especialista pela sociedade correspondente, vinculação com Universidade (docência e/ou preceptoria) e nacionalidade;

2) Identificar o conhecimento dos médicos da APS acerca da $P Q$ em áreas estratégicas desse nivel de atenção à saúde: saúde da criança, saúde da mulher, saúde do idoso e saúde do homem.

Avaliação dos Riscos e Beneficios:

Como bem colocado pelas pesquisadoras, os participantes do estudo não terăo benefícios diretos; entretanto, os resultados da pesquisa permitirão que se apontem e divulguem aspectos importantes da $\mathrm{PQ}$ entre os médicos que atuam na APS, beneficiando diretamente os pacientes sob responsabilidades desses profissionais, especialmente no que tange a prevenção de terapêuticas e procedimentos desnecessários junto à população.

Em relação aos riscos, eles são mínimos, mas sempre existem. Ao lado de um potencial "incômodo" ao se responder o questionário - convenientemente citado no termo de consentimento livre e esclarecido (TCLE) pelas pesquisadoras -, há sempre o risco da quebra de sigilo, por vazamento acidental dos dados - apesar de todos os cuidados a serem tomados. Como solicitado no parecer anterior deste Comitê de Ética em Pesquisa (CEP), este risco foi descrito nos TCLEs, tanto no dos juizes quanto no dos participantes.

\section{Comentários e Consideraçőes sobre a Pesquisa:}

Trata-se de um projeto de relevância em saúde pública que visará estudar o conhecimento sobre $P Q$ entre os médicos que atuam na APS em todo o Brasil.

Entretanto, seria interessante mais um comentário. Pelo que se póde compreender na leitura do projeto, o instrumento (entrevista), antes de ser utilizado pelos participantes da pesquisa, será validado por dois juizes. Dessa forma, entendemos que o instrumento poderá vir a ser modificado após a análise desses dois profissionais. Se isso ocorrer, o projeto deverá ser analisado novamente por esse CEP.

\section{Consideraçöes sobre os Termos de apresentação obrigatória:}

Todas as modificaçōes solicitadas no parecer anterior (a saber: citação do risco de quebra acidental do sigilo nos TCLEs, inserção dos contatos do pesquisador e correçáo do endereço e do telefone do CEP) foram atendidas.

Recomendaçöes:

Nada a acrescentar.

Endereç: TERESINA 690

Bairro: SUMAREZINHO CEP: $14.055-390$

UF: SP Municipio: RIBEIRAO PRETO

Telefone: (16)3315-0009

E-mail: csecuiaba@imp.usp.tr 


\section{USP - CENTRO DE SAÚDE ESCOLA DA FACULDADE DE MEDICINA DE RIBEIRÃO

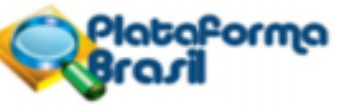

Cortinuacto do Parecer. 3.132660

Conclusőes ou Pendências e Lista de Inadequaçőes:

Por terem sido atendidas todas as pendências apontadas no parecer anterior por este CEP, sugro a aprovaçåo do projeto no que tange ao quesito ético.

Consideraçöes Finais a critério do CEP:

PRONETO APROVADO

Este parecer foi elaborado baseado nos documentos abaixo relacionados:

\begin{tabular}{|c|c|c|c|c|}
\hline Tipo Documento & Arquivo & Postagem & Autor & Situação \\
\hline $\begin{array}{l}\text { Informações Básicas } \\
\text { do Projeto }\end{array}$ & $\begin{array}{l}\text { PB_INFORMAÇOES_BASICAS_DO_P } \\
\text { ROJETO 1244333,pdf }\end{array}$ & $\begin{array}{c}15 / 01 / 2019 \\
23: 54: 02\end{array}$ & & Aceito \\
\hline \begin{tabular}{l|l} 
Outros & \\
\end{tabular} & carta_cep_pend.doc & $\begin{array}{c}15 / 01 / 2019 \\
23: 53: 39\end{array}$ & $\begin{array}{l}\text { Janise Braga Barros } \\
\text { Ferreira }\end{array}$ & Aceito \\
\hline $\begin{array}{l}\text { TCLE / Termos de } \\
\text { Assentimento / } \\
\text { Justificativa de } \\
\text { Ausência }\end{array}$ & TCLE_Medicos_APS_corrigido.docx & $\begin{array}{c}15 / 01 / 2019 \\
23: 30: 02\end{array}$ & $\begin{array}{l}\text { Janise Braga Barros } \\
\text { Ferreira }\end{array}$ & Aceito \\
\hline $\begin{array}{l}\text { TCLE / Termos de } \\
\text { Assentimento / } \\
\text { Justificativa de } \\
\text { Ausência }\end{array}$ & TCLE_Juizes_corrigido.docx & $\begin{array}{c}15 / 01 / 2019 \\
23: 29: 41\end{array}$ & $\begin{array}{l}\text { Janise Braga Barros } \\
\text { Ferreira }\end{array}$ & Aceito \\
\hline Folha de Rosto & Folha_rosto.pdf & $\begin{array}{c}25 / 10 / 2018 \\
21: 39: 22 \\
\end{array}$ & $\begin{array}{l}\text { Janise Braga Barros } \\
\text { Ferreira }\end{array}$ & Aceito \\
\hline Outros & Instrumento.pdf & $\begin{array}{c}25 / 10 / 2018 \\
12: 47: 32\end{array}$ & $\begin{array}{l}\text { Janise Braga Barros } \\
\text { Ferreira }\end{array}$ & Aceito \\
\hline Outros & Carta_Convite_Juizes.pdf & $\begin{array}{c}25 / 10 / 2018 \\
12: 46: 16 \\
\end{array}$ & $\begin{array}{l}\text { Janise Braga Barros } \\
\text { Ferreira }\end{array}$ & Aceito \\
\hline $\begin{array}{l}\text { TCLE / Termos de } \\
\text { Assentimento / } \\
\text { Justificativa de } \\
\text { Ausência }\end{array}$ & TCLE_medicos.pdf & $\begin{array}{c}25 / 10 / 2018 \\
12: 42: 15\end{array}$ & $\begin{array}{l}\text { Janise Braga Barros } \\
\text { Ferreira }\end{array}$ & Aceito \\
\hline Orçamento & Orcamento.pdf & $\begin{array}{c}25 / 10 / 2018 \\
11: 47: 22 \\
\end{array}$ & $\begin{array}{l}\text { Janise Braga Barros } \\
\text { Ferreira }\end{array}$ & Aceito \\
\hline Cronograma & Cronograma.docx & $\begin{array}{c}25 / 10 / 2018 \\
11: 46: 52 \\
\end{array}$ & $\begin{array}{l}\text { Janise Braga Barros } \\
\text { Ferreira }\end{array}$ & Aceito \\
\hline $\begin{array}{l}\text { TCLE / Termos de } \\
\text { Assentimento / } \\
\text { Justificativa de } \\
\text { Ausência }\end{array}$ & TCLE_Juizes.pdf & $\begin{array}{c}24 / 10 / 2018 \\
15: 31: 40\end{array}$ & $\begin{array}{l}\text { Janise Braga Barros } \\
\text { Ferreira }\end{array}$ & Aceito \\
\hline $\begin{array}{l}\text { Projeto Detalhado/ } \\
\text { Brochura } \\
\text { Investigador }\end{array}$ & ProjetoMestradoFinal.pdf & $\begin{array}{c}24 / 10 / 2018 \\
15: 30: 53\end{array}$ & $\begin{array}{l}\text { Janise Braga Barros } \\
\text { Ferreira }\end{array}$ & Aceito \\
\hline
\end{tabular}

Endereç: TERESINA 690

Bairro: SUMAREZINHO
UF: SP $\quad$ Municipio: RIBEIRAO PRETO

Telefone: (16)3315-0009

E-mail: csecuiaba@fmp.usp.tr 


\section{USP - CENTRO DE SAÚDE ESCOLA DA FACULDADE DE MEDICINA DE RIBEIRÃO}

Cortinuaço do Parecer: 3.132660

Situaçăo do Parecer:

Aprovado

Necessita Apreciaçăo da CONEP:

Não

RIBEIRAO PRETO, 05 de Fevereiro de 2019

Assinado por:

LAÉRCIO JOEL FRANCO

(Coordenador(a))

Endereço: TERESINA 690

Bairro: SUMAREZINHO

CEP: $14.055-380$

UF: SP

Municipio: RIBEIRAO PRETO

Telefone: (16)3315-0009 
ANEXO B - Comprovante de submissão do artigo

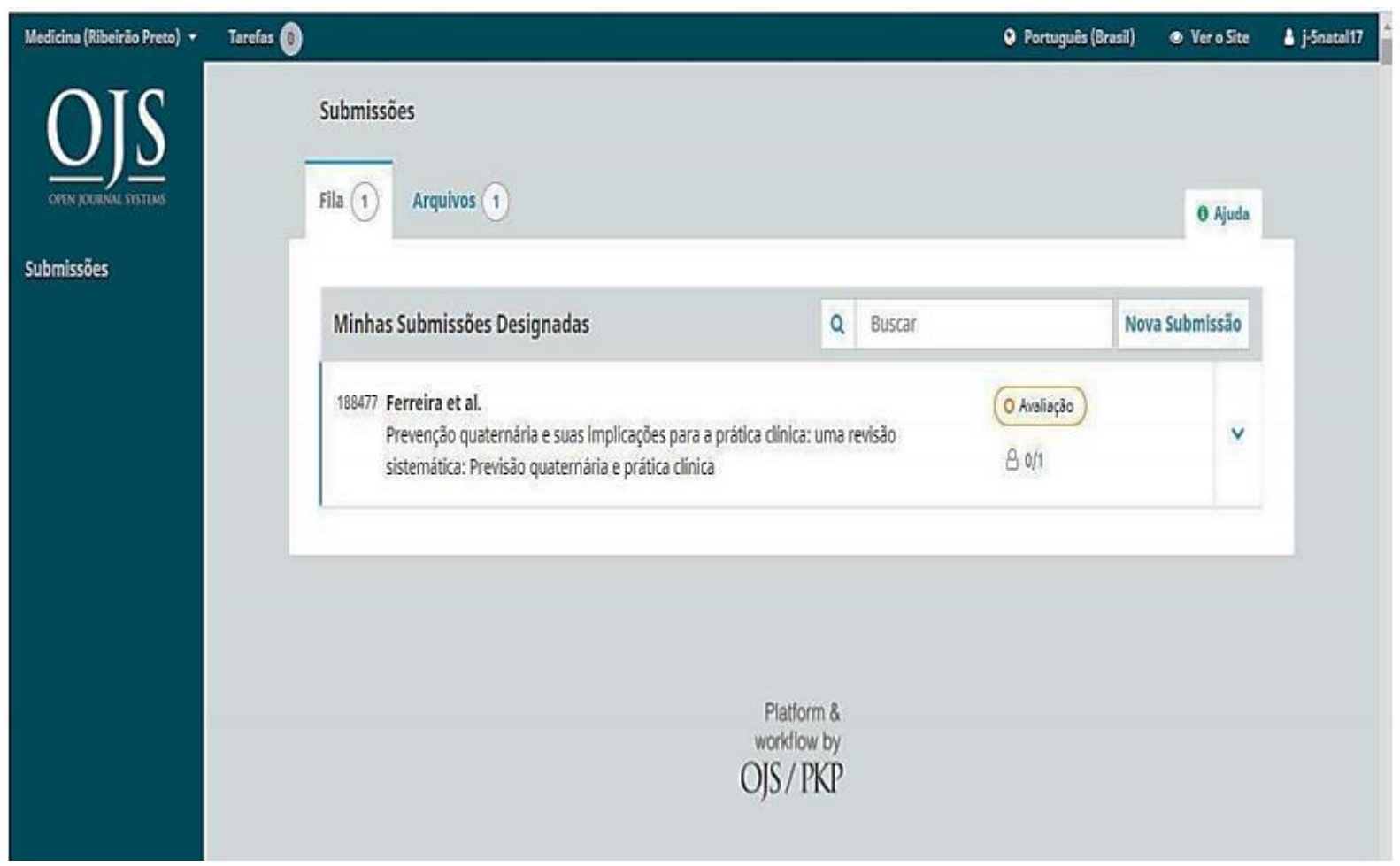

